\title{
Guadix y sus mujeres: promoción femenina en la arquitectura religiosa de la Edad Moderna
}

\author{
María Encarnación Hernández LóPeZ
}

Fecha de recepción: Junio 2020.

Fecha de aprobación: Septiembre 2020.

\section{Sumario:}

Este artículo analiza la participación de las mujeres en la promoción de arquitectura religiosa en la ciudad de Guadix durante el siglo XVI e inicios del XVII. Partiendo de diversa documentación de archivo y de bibliografía de la época, se ha recuperado su intervención en las distintas tipologías que conforman el ámbito de la arquitectura religiosa. En este contexto, se las ha documentado remodelando y promoviendo capillas dentro de la catedral e iglesias de esta ciudad, como fundadoras de colegios y conventos e, incluso, firmando contratos de obras; en este caso como parte de un proyecto más ambicioso.

\section{Palabras clave:}

Historia de las Mujeres; Historia de la Construcción; Capilla; Mecenazgo; Fundación; Colegio Jesuita.

\section{Guadix and its women: female promotion in the religious architecture of the Modern Age}

\begin{abstract}
:
This article analyzes the participation of women in the promotion of religious architecture in the city of Guadix during the sixteenth century in the early seventeenth. Starting from various archival documentation and bibliography of the time, their intervention in the different typologies that make up the field of religious architecture has been recovered. In this context, they have been documented remodeling and promoting chapels within the cathedral and churches of this city, as founders of schools and convents and, even, signing works contracts; in this case as part of a more ambitious project.
\end{abstract}

\section{Keywords:}

Women's History; Construction History; Chapel; Patronage; Foundation; Jesuit College.

\footnotetext{
${ }^{1}$ Doctora en Historia y Artes por la Universidad de Granada. Investigador independiente. https://orcid.org/0000-0002-1510-0165<enc.hernandez@gmail.com>.
} 


\section{Introducción}

A día de hoy, pese al surgimiento de interesantes estudios al respecto, la intervención de las mujeres en el ámbito de la arquitectura continúa siendo en gran medida desconocida. En el caso de la ciudad de Guadix, no existe estudio alguno dedicado, ni siquiera parcialmente, a este aspecto. Es por ello que nos propusimos recuperar la labor desarrollada en este campo por las mujeres que vivieron o tuvieron algún contacto con esta ciudad durante el siglo XVI e inicios del XVII.

Centrándonos en el ámbito de la arquitectura religiosa, recuperamos a lo largo de las siguientes páginas los nombres propios de varias mujeres que ejercieron en la ciudad de Guadix labores de promoción y mecenazgo arquitectónico; contribuyendo con ello a cambiar, de manera definitiva, la fisonomía de la ciudad medieval islámica. Nos acercaremos a ellas a través de los datos biográficos que hemos podido obtener en diferentes archivos; pero sobre todo, a través de sus proyectos arquitectónicos en iglesias y capillas o como fundadoras y constructoras de monasterios, conventos y colegios. En las siguientes líneas rescatamos del olvido a varias de ellas. Sin embargo, somos muy conscientes de que fueron muchas más de las que presentamos las que participaron en la arquitectura de la ciudad y confiamos en que irán surgiendo en futuras investigaciones.

Este estudio está centrado en la ciudad de Guadix. Una ciudad modesta en cuanto a tamaño, pero de gran importancia a lo largo de la historia y durante la Edad Moderna. Tras la conquista cristiana se asentaron en ella una serie de familias influyentes, cuyos miembros, hombres y mujeres, intervinieron activamente en su trama urbana.

Iniciamos este estudio delimitando someramente el marco histórico en el que se desarrolló la vida de las mujeres objeto de nuestro estudio, ya que éste condicionó su vida y su capacidad de actuación. Seguidamente, nos centramos en el análisis de la biografía y de la labor de mecenazgo o promoción arquitectónica llevada a cabo por ellas. La mayor parte de la información aquí presentada es inédita, ya que procede de diversos documentos custodiados en varios archivos. Esta ha sido completada y ampliada tanto con bibliografía de la época como con publicaciones de carácter más reciente.

\section{Guadix en los inicios de la Edad Moderna. Algunos aspectos históricos sobre la ciudad y sus mujeres}

Tras el sitio de Baza, el bastión de Granada por el noreste se hundió. Como consecuencia de ello, en diciembre de 1489 Muhammad XII Al-Zagal entregó 
por capitulación el resto de su efímero reino y, en concreto, las plazas de Almería y Guadix ${ }^{2}$. El proceso de castellanización y cristianización de la Guadix medieval islámica comenzó con un plan del rey Fernando que contemplaba el que se instalaran de manera inmediata en la ciudad hasta 2.000 vecinos, a los que se les ofrecería casa, huerta, viña y tierra de labranza. A todos ellos, además, se les garantizaría el culto cristiano mediante la consagración de iglesias y monasterios. Tras medir la tierra fue necesario cambiar la previsión real de repobladores, recortándola a 800, más los que pudieran resultar de la concesión posterior de mercedes. A esta población habría que sumar la de los mudéjares asentados en la morería. Finalmente, el reparto se llevó a cabo de forma desordenada y los nuevos pobladores se aferraron a la riqueza rústica, urbana y mueble dejada por los musulmanes ${ }^{3}$.

\subsection{Las repobladoras cristianas}

De los 625 vecinos o cabezas de familia que finalmente se asentaron en la ciudad, constituyendo su población de arranque, conocemos que 28 de ellos fueron mujeres. Probablemente se trataba de viudas de escuderos y caballeros que participaron en la conquista de la ciudad y que obtuvieron la vecindad como pago a los servicios prestados por sus maridos en la Guerra de Granada. Estas mujeres castellanas llegaron formando parte del primer contingente de repobladores a un lugar desconocido, en el que eran minoría y en el que debían dar testimonio de nuevas formas de vida y ser referentes de la mujer cristiana. La bibliografía al respecto señala que las mujeres musulmanas tuvieron que acatar las nuevas leyes sobre el matrimonio, la familia, la herencia o la manera de vivir la religión y renunciar a su manera de vestir, a su alimentación, a sus ritos de vida, a sus costumbres e incluso su casa. En cuanto a las mujeres judías señala también que éstas abandonaron la ciudad junto a los suyos después del decreto de expulsión que los Reyes Católicos dictaron en $1492^{4}$. Nosotros creemos fue probable el que se dieran otras situaciones.

Del grupo de repobladoras que por merced real obtuvieron vecindad en Guadix de manera directa o en nombre de hombres difuntos, conocemos sus

${ }^{2}$ Cf. Carlos Asenjo Sedano, Guadix, siglo XV: Plaza de los Corregidores (Granada: Aula de Cultura del Movimiento, 1975), 11-27.

${ }^{3}$ Carlos Asenjo Sedano, Guadix, la ciudad musulmana del siglo XV y su transformación en la ciudad neocristiana del siglo XVI (Granada: Diputación Provincial, 1983), 255-257.

${ }^{4}$ María Socorro Robles Vizcaíno, «Las mujeres en la castellanización de Guadix y el Marquesado del Zenete», en Las mujeres en la Historia: Itinerarios por la Provincia de Granada, ed. por María Socorro Robles Vizcaíno y Margarita Birriel Salcedo (Granada: Universidad de Granada, 2012), 227. 
nombres; no así el de aquellas que se asentaron junto a sus maridos y que quedaron ocultas tras el nombre del varón. La repobladoras de Guadix fueron: Cetevina Uli, mujer de Aduladín ${ }^{5}$; las viudas de escuderos Leonor Núñez, Catalina de Matamoros y Leonor Gutiérrez. Inés de Mescua, la mujer de Navarrete, Francisca Mesa y María Ruiz. Además de ellas, encontramos otras de alta alcurnia como la Marquesa de Ugarte, viuda de Fernán Cueva, la marquesa de Barthe o Constanza de Pineda, mujer del conde García Martín. Otras fueron Juana Hurtado; María de Granada, cristiana nueva; Inés Delgadillo; Mari Sánchez, mujer de Juan Coracho; Mencía de Guzmán; Leonor Núñez; Elvira Martínez Pareja; María Dávalos y su hermana; Catalina de Montano; María de Medina, ayudante de la panadería de los Reyes Católicos; María Ruiz; Leonor de Ayllón; María de Perea; Marina de Peñuela; Marina de la Cueva y la mujer de Juan Sarabia 6 .

De esta lista de mujeres repobladoras sabemos que diecisiete de ellas recibieron mercedes reales por las que se le asignaron casas y tierras. Como consecuencia de estas asignaciones, algunas de ellas llegaron a gestionar grandes patrimonios. En el siguiente cuatro presentamos a estas mujeres receptoras de mercedes reales en Guadix tras su conquista ${ }^{7}$.

\section{Mujeres receptoras de mercedes reales en Guadix}

\begin{tabular}{|l|c|l|l|}
\hline \multicolumn{1}{|c|}{ Nombre } & Fecha & \multicolumn{1}{|c|}{ Patrimonio asignado } & $\begin{array}{l}\text { Valor } \\
\text { (mrs.) }\end{array}$ \\
\hline $\begin{array}{l}\text { Mencía de Guzmán, hija de } \\
\text { Alonso Guzmán }\end{array}$ & $26-5-1491$ & $\begin{array}{l}\text { Una casa, un horno, 4 cármenes, } \\
\text { 54 fanegas de tierra, 5 aranza- } \\
\text { das de viña, un majuelo y 100 } \\
\text { morales. }\end{array}$ & 100.500 \\
\hline Francisca de Mesa & $31-5-1491$ & $\begin{array}{l}\text { Unas casas, un carmen, tres cuar- } \\
\text { tas de viña y 23 morales. }\end{array}$ & 3.900 \\
\hline $\begin{array}{l}\text { María de Medina } \\
\text { de la panadería de los reyes }\end{array}$ & $5-8-1491$ & $\begin{array}{l}\text { Unas casas, 22 morales, 150 esta- } \\
\text { dales de carmen, aranzada y me- } \\
\text { dia de viña y 24 fanegas de tierra }\end{array}$ & 24.000 \\
\hline
\end{tabular}

${ }^{5}$ En la documentación se especifica que es mora.

${ }^{6}$ Asenjo Sedano, Guadix, la ciudad musulmana..., 259-273.

${ }^{7}$ Ibidem, 276-291.

${ }^{8}$ Además de las mercedes que se le concedieron en Guadix, conocemos que en el año 1500 los reyes otorgaron a María de Medina, criada de la reina, una merced por la cual le asignaban una casa en la Alhambra. La casa lindaba con el monasterio de San Francisco, con otras casas de los reyes, con la casa del panadero del Conde de Tendilla y con la calle pública. Cf. María Elena Díez Jorge, «Casas en la Alhambra después de la conquista cristiana (1492-1516): pervivencias medievales y cambios», en La casa medieval en la península ibérica, ed. por María Elena Díez Jorge y Julio Navarro Palazón (Madrid: Sílex, 2015), 402 y 426. 


\begin{tabular}{|c|c|c|c|}
\hline $\begin{array}{l}\text { María Sánchez, mujer de } \\
\text { Juan Coracho }\end{array}$ & $20-11-1491$ & - & 30.000 \\
\hline $\begin{array}{l}\text { Inés de Mescua, mujer de } \\
\text { García de Navarrete, escude- } \\
\text { ro de las Guardas }\end{array}$ & 07-03-1492 & $\begin{array}{l}\text { Unas casas, una aranzada y cuar- } \\
\text { ta y media de viña, } 36 \text { fanegas de } \\
\text { tierra, un carmen y } 22 \text { morales. }\end{array}$ & 21.800 \\
\hline $\begin{array}{l}\text { Catalina de Montañas, mujer } \\
\text { de Juan Díaz de Navarrete, } \\
\text { escudero de las Guardas }\end{array}$ & 07-03-1492 & $\begin{array}{l}10 \text { fanegas de tierra, } 10 \text { morales, } \\
\text { un carmen y aranzada y cuarta de } \\
\text { viña. }\end{array}$ & 14.500 \\
\hline $\begin{array}{l}\text { María de Ávalos y su herma- } \\
\text { na, Catalina Fernández }\end{array}$ & $02-05-1492$ & Tres aranzadas y cuarta de viña ${ }^{9}$. & 5.000 \\
\hline $\begin{array}{l}\text { La mujer e hijo de Pedro de } \\
\text { Lisón }\end{array}$ & $15-05-1492$ & Unas casas y 20 fanegas de tierra. & 44.000 \\
\hline María de Granada & $23-05-1492$ & $\begin{array}{l}\text { Las casas de Albiñana, } 24 \text { fane- } \\
\text { gas de tierra, aranzada y media } \\
\text { de viña, } 22 \text { morales y } 250 \text { estada- } \\
\text { les de carmen. }\end{array}$ & 18.800 \\
\hline $\begin{array}{l}\text { Leonor de Ayllón, hija de } \\
\text { Mari Gutiérrez de Jaén }\end{array}$ & $23-5-1492$ & $\begin{array}{l}\text { Unas casas, aranzada y media de } \\
\text { viña, } 24 \text { fanegas de tierra, } 22 \text { mo- } \\
\text { rales y } 100 \text { estadales de carmen }\end{array}$ & 21.100 \\
\hline $\begin{array}{l}\text { María de Pereda, mujer de } \\
\text { García de Garay, escudero } \\
\text { de las Guardas }\end{array}$ & $25-5-1492$ & $\begin{array}{l}50 \text { fanegas de tierras, unas ca- } \\
\text { sas; aranzada y media de viña, } \\
130 \text { estadales de carmen y } 24 \\
\text { morales. }\end{array}$ & 24.800 \\
\hline $\begin{array}{l}\text { Constanza de Pineda, mu- } \\
\text { jer de un escudero de las } \\
\text { Guardas }\end{array}$ & $25-05-1492$ & $\begin{array}{l}\text { Unas casas, una tienda, } 2 \text { fanegas } \\
\text { de tierra, un carmen, aranzada y } \\
\text { media de viña y } 22 \text { morales. }\end{array}$ & 31.250 \\
\hline $\begin{array}{l}\text { Juana Hurtado, mujer de } \\
\text { Vozmediano, vecino de } \\
\text { Madrid }\end{array}$ & $3-2-1492$ & - & 40.000 \\
\hline $\begin{array}{l}\text { Mariana Ruiz, mujer de Feli- } \\
\text { pe Segovia }\end{array}$ & $4-05-1496$ & $\begin{array}{l}\text { Unas casas, aranzada y media de } \\
\text { viña, } 24 \text { fanegas de tierra, un car- } \\
\text { men y } 25 \text { morales. }\end{array}$ & 23.000 \\
\hline $\begin{array}{l}\text { Leonor Núñez, hija del ba- } \\
\text { chiller Alonso Núñez, físico } \\
\text { de los reyes }\end{array}$ & $\begin{array}{c}\text { Fecha } \\
\text { desconocida }\end{array}$ & $\begin{array}{l}\text { Unas casas, } 3 \text { aranzadas de viña, } \\
71 \text { fanegas de tierra, } 44 \text { morales, } \\
2 \text { tiendas, unas cuevas, un corral } \\
\text { y } 3 \text { tahúllas de carmen. }\end{array}$ & 44.000 \\
\hline $\begin{array}{l}\text { Marquesa de Ugarte, mujer } \\
\text { de Fernando de Covarrubias, } \\
\text { maestresala de los reyes }\end{array}$ & $\begin{array}{c}\text { Fecha } \\
\text { desconocida }\end{array}$ & - & 202.460 \\
\hline
\end{tabular}

Fuente: elaboración propia según lo contenido en la obra Asenjo Sedano, Guadix, la ciudad musulmana..., 276-291.

\footnotetext{
${ }^{9}$ Carlos Asenjo precisa que se le dio mucho más.
} 
Estas mujeres, viudas en su mayoría, que sumaron a las propiedades de sus lugares de origen las nuevas obtenidas en Guadix, fueron por tanto gestoras de grandes patrimonios ${ }^{10}$.

\subsection{La transformación urbana de la ciudad}

La transformación del urbanismo de la ciudad no va a abarcar íntegramente toda ella. La temprana edificación de los conventos, por sus grandes volúmenes arquitectónicos y sus alturas impusieron al urbanismo tradicional musulmán unas perspectivas nuevas ${ }^{11}$. Todas las mezquitas quedaron para los conquistadores y la Iglesia católica pasó a ser casi automáticamente la nueva propietaria de sus edificios y de sus propiedades. Las mezquitas dejaron de ser mezquitas para convertirse en iglesias. Así surgen las iglesias Mayor o catedral, la de San Miguel, la de Santa María Magdalena, la de Santiago, la de Santa Ana, la de San Pedro, la de San Juan, la de Santa Isabel, la de la Santa Cruz, la de Santa Catalina y la de San Marcos ${ }^{12}$. La sinagoga judía fue transformada en Hospital Real cuya gestión se encomienda al Cabildo catedralicio. La alcazaba, elemento fundamental de la ciudad musulmana, fue también modificada. La muralla de la ciudad islámica experimentó una progresiva degradación al demolerse un paño de la misma para construir la catedral. En muchas de sus torres se instalaron viviendas. Sin embargo, la segunda cerca prácticamente subsistió hasta el siglo XIX. El espacio medieval de Bib-almazán fue ensanchado mediante la demolición de muchas tiendas situadas en ella para instalar allí la actual Plaza Mayor de la ciudad, surgiendo allí el centro administrativo y político de la ciudad cristiana ${ }^{13}$.

Desde el punto de vista arquitectónico y tipológico, los conquistadores hicieron valer sus derechos y levantaron edificios para satisfacer las nuevas necesidades. Según Gómez-Moreno Calera, como la arquitectura mudéjar estaba plenamente implantada en sus territorios de origen, estos adaptaron

${ }^{10}$ Estas mercedes fueron dadas a hombres y a mujeres, sin embargo, nosotros solamente presentamos a las mujeres merecedoras de mercedes reales, dado que este estudio se centra en el estudio de éstas.

${ }^{11}$ Para conocer cómo se desarrollaba la cotidianeidad de los repobladores de Guadix a finales del siglo XV resulta de gran relevancia los trabajos: Manuel Espinar Moreno, María Angustias Álvarez del Castillo y María Dolores Guerrero Lafuente, La ciudad de Guadix en los siglos XV y XVI (1490-1515) (Granada: Ayuntamiento de Guadix, Universidad de Granada, 1992). Manuel Espinar Moreno, «La vida diaria de los repobladores de Guadix en noviembre de 1496», Revista del Centro de Estudios Históricos de Granada y su Reino 15 (2001): 35-39.

\footnotetext{
${ }^{12}$ Asenjo Sedano, Guadix, la ciudad musulmana..., 304-305.

${ }^{13}$ Ibidem, 315-316.
} 
los distintos repertorios artísticos sin diferencias apreciables salvo algunos matices ${ }^{14}$.

Constatamos también la participación activa de las mujeres en el proceso de castellanización y cristianización de la ciudad medieval islámica de Guadix. Repobladoras cristianas (esposas, viudas, hijas) que dentro del papel asignado en una sociedad patriarcal, aprovecharon su posición social en muchos casos y los resquicios que les dejaron las leyes y las normas establecidas, para promover arquitectura tanto civil como religiosa. La promoción y mecenazgo arquitectónico ejercido por ellas, unido al que ejercieron los hombres terminaría por cambiar de manera definitiva la fisionomía de la ciudad como analizaremos en los siguientes epígrafes.

\subsection{Las mujeres según el Sínodo de la diócesis de Guadix y de Baza de 1554}

Si bien la situación jurídica de las mujeres en la Edad Moderna está ampliamente estudiada, nos detenemos a analizar algunas cuestiones que sobre las mujeres estipula el Sínodo de Guadix-Baza de 1554. Los preceptos marcados por éste van a condicionar algunos aspectos de la vida de las mujeres de esta diócesis, al ser de obligado cumplimiento.

El sínodo convocado en Guadix por Martín Pérez de Ayala ha pasado a la historia como el más importante de los celebrados en la diócesis de Guadix y el primero «celebrado en el interior del Reino de Granada desde que éste se había anexionado a la corona de Castilla» ${ }^{15}$. En él se aborda todo un conjunto de temas relacionados con la reforma de la vida cristiana, partiendo de los decretos del Concilio de Trento, en cuyas deliberaciones había participado. Pérez de Ayala, como otros obispos asistentes al Concilio de Trento, regresó con la intención de aplicar en su diócesis las doctrinas y reformas allí promulgadas. Es por eso que la visitó antes casi en su totalidad ${ }^{16}$. El sínodo tuvo lugar durante veinte días (del 22 de enero al 10 de febrero de 1554), en las «casas obispales» de Guadix, celebrando treinta y dos sesiones. A los tres días de su terminación se publicaron en la catedral las Constituciones. Con un total de 254, se agrupaban en ocho títulos, que abarcan prácticamente todos los aspectos de la vida diocesana. En ellas se observa una preocupación preferente

${ }^{14}$ José Manuel Gómez-Moreno Calera, Arquitectura Mudéjar en la Comarca de Guadix (Guadix: Centro de Iniciativas Turísticas de la Comarca de Guadix, 2009), 35.

${ }^{15}$ Antonio Gallego y Burín y Alfonso Gamir Sandoval, Los moriscos del Reino de Granada según el Sínodo de Guadix de 1554 (Granada: Universidad de Granada, 1996), 9.

${ }^{16}$ Leovigildo Gómez Amezcua, «La pastoral del bautismo en el Sínodo de 1554», Boletín del Centro de Estudios Pedro Suárez 24 (2011): 61-65. 
por los moriscos, neoconversos que formaban la mayoría de la población de la diócesis y que, tras un largo periodo de dominación cristiana, «todavía conservaban, casi en su integridad, lengua, costumbres, usos y ceremonias, más arraigadas aún por la clandestinidad en que las practicaban» ${ }^{17}$.

Si bien la mayoría de los preceptos del sínodo estaban dirigidos a esta población morisca, eran de obligado cumplimiento para toda la población. Es por ello que este documento nos ofrece una información muy valiosa de algunos aspectos de la vida de los habitantes de los territorios adscritos a la diócesis de Guadix-Baza durante la segunda mitad del siglo XVI. Resultan de gran interés para esta investigación las constituciones dedicadas a ordenar y vigilar la vida de las mujeres.

El control ejercido por la Iglesia hacia las mujeres se iniciaba ya en la infancia, atribuyendo a las niñas obligaciones como la asistencia a misa. El texto recoge el hecho de que las doncellas de diez o doce años iban a misa los sábados y no los domingos. Esto suponía un gran inconveniente, pues incumplían la obligación de asistir a misa los domingos y las privaba de los sermones que se predicaban. Además de ello, al quedarse esos días en sus casas solas y trabajando, contravenían el precepto de la Iglesia que establecía no trabajar esos días. Es por ello que el sínodo ordena que todas las doncellas de doce años en adelante fueran con sus madres a la misa mayor de los domingos y fiestas de guardar ${ }^{18}$.

Otro de los aspectos que quedaba regulado en el sínodo y que afectaba a las mujeres directamente era el matrimonio. El documento lo define como un sacramento que consiste en un «ayuntamiento legítimo» e indisoluble de hombre y mujer; que han de tener una vida común e indivisa casi en todas las cosas. Además en él debían de concurrir tres factores: fidelidad; amor recíproco del hombre a la mujer y de la mujer al marido, y cuidado común de criar los hijos cristianamente ${ }^{19}$. Resulta llamativa la obligación de ambos cónyuges del cuidado común de los hijos, si bien esta era una labor que mayoritariamente realizaban las mujeres. Por otra parte, la indisolubilidad estipulada para el matrimonio vino a afectar especialmente a las mujeres casadas que tenían maridos ausentes durante mucho tiempo. Estas, según el sínodo, no podían casarse de nuevo hasta que presentaran a los provisores de la Iglesia varios

${ }^{17}$ Gallego y Burín y Gamir Sandoval, Los moriscos..., 29.

${ }^{18}$ Martín de Ayala, Synodo de la Diocesi de Guadix y de Baça (Alcalá de Henares: Casa de Iuan de Brocar, 1554). Edición facsímil de la Universidad de Granada de 1996 con estudio preliminar de Carlos Asenjo Sedano. Título VI, fol. LIv. Hombres y mujeres estaban obligados a ir a misa todos los domingos y fiestas de guardar a partir de los catorce años. Pero según se recoge en este título, la obligación de las mujeres se adelantaba a los doce años.

${ }^{19}$ Ibidem, título VI, fol. XXv. 
testigos que dieran fe de la muerte de su marido, además de una probanza o certificación de que había fallecido ${ }^{20}$. Esta situación provocó que muchas mujeres, que habían perdido a su marido en guerras u otras circunstancias y que no podían probar su fallecimiento, quedaran en total desamparo.

Otras circunstancias que afectaban la intimidad de las mujeres y que reguló el sínodo fueron aspectos relacionados con el parto y el postparto. Se estableció que el parto debía ser atendido por una cristiana vieja y que las recién paridas sólo podían salir para dar gracias a Dios por su hijo a la parroquia donde la criatura había sido bautizada. Esta primera salida debía hacerse dentro del primer mes después del parto. En el caso de que en este periodo la mujer no estuviera recuperada, tendría que hacerlo dentro del mes y medio posterior ${ }^{21}$.

Preocupación fundamental de los padres del sínodo fue la salvaguarda de la decencia y la honestidad de las mujeres. Es por esto que también regulan el sacramento de la confesión para ellas. Con el fin de que no estuvieran muy cerca del confesor, lo cual «es manifiesta indecencia y deshonestidad», las mujeres menores de cuarenta años y mayores de catorce debían confesarse en el confesionario de sus parroquias. En el caso de no existir confesionario, debían ser oídas en confesión públicamente en el cuerpo de la iglesia. Se especifica de manera clara que no se debía administrar este sacramento en rincones ni capillas secretas ${ }^{22}$. La juventud de la mujer, y por tanto la etapa donde más peligro corrían de ser deshonestas, queda estipulada entre los 14 y los 40 años.

Especial inquietud despertaron también las «mujeres sospechosas» que atentaban contra la honestidad y que vivían con los clérigos. Consideraban mujer sospechosa a aquella que vivía con un clérigo y no era madre ni hermana ni hija de hermano o hermana ni tía, hermana del padre o madre. También era considerada sospechosa toda mujer que no pasase de cuarenta y cinco años y que fuera de «buen parecer», si no estaba casada. En sus visitas, Martín Pérez de Ayala había constatado cómo los clérigos vivían con mujeres ataviadas con mil colores, hecho que condenaba enérgicamente ${ }^{23}$. Por contraposición, este último precepto pone de manifiesto que las buenas cristianas accitanas no debían vestir con trajes coloridos.

Las mujeres sobre las que cayó todo el peso del sínodo fueron las alcahuetas. Definidas como mujeres viles, con poco temor a Dios y que acostumbran a ser «intervenidoras», llevando y trayendo mensajes y tratos ilícitos entre hombres y mujeres en perjuicio de la honestidad. Y aquellas otras que tenían

\footnotetext{
${ }^{20}$ Ibid. Título VI, fol. XXIIv.

${ }^{21}$ Ibid. Título II, fol. VIv y fol. VII.

${ }^{22}$ Ibid. Título II, fol. XII.

${ }^{23}$ Ibid. Título V, fol. XLVIIIv.
} 
por costumbre recibir en sus casas a hombres y mujeres que ilícitamente «se quieren conuersar». El sínodo estipuló que la persona que fuese hallada en semejantes tratos, si amonestada una vez no desistía de ello, sería azotada públicamente o desterrada de la diócesis ${ }^{24}$.

Finalmente, el recato de las mujeres recluidas en los conventos y monasterios quedaba también protegido al estipularse que en ellos no podía entrar hombre alguno; salvo que éste fuese confesor, médico, mayordomo de algún monasterio u hombre muy anciano o de mucho crédito ${ }^{25}$. Bajo todas estas normas morales $-\mathrm{y}$ algunas más que afectaban tanto a hombres como mujeres $^{26}$ - y bajo las leyes establecidas, se va a desarrollar la vida de las mujeres accitanas durante la segunda mitad del siglo XVI y todo el siglo XVII.

\section{Promotoras de arquitectura religiosa}

Es en este contexto histórico-espacial que hemos descrito donde las mujeres ejercieron su labor promotora. Presentamos a continuación el estudio de caso de varias de ellas que participaron en la promoción de diferentes tipologías arquitectónicas de carácter religioso. Estas van desde la construcción de capillas a la fundación de colegios o conventos. Precediendo a su labor constructiva y/o fundacional, ofrecemos sus datos biográficos que hemos obtenido a través de diversa documentación de archivo. Precisamos que, si bien este estudio, como decíamos, está centrado en el análisis de la arquitectura religiosa promovida por mujeres, en nuestra labor de investigación las hemos documentado participando también en la promoción de arquitectura civil.

3.1. Mujeres en la construcción de la catedral de Guadix: el caso de la «capilla de Don Tadeo»

Tras la conquista de la ciudad de Guadix, las mezquitas fueron ocupadas. Las pequeñas se convirtieron en viviendas de los nuevos pobladores, mientras que las de un mayor tamaño se transformaron en iglesias cristianas. En la mezquita Mayor se instaló la iglesia Mayor o de Santa María, dedicada a Santa María de la Encarnación. Terminada la conquista de Granada, el Gran Cardenal, Pedro González de Mendoza expidió en la Alhambra, el día 21 de

\footnotetext{
${ }^{24}$ Ibid. Título VI, fol. LXVIr.

${ }^{25}$ Ibid. Título V, fol. XLVIIv.

${ }^{26}$ Muchas de las normas morales impuestas en el sínodo de 1554 estuvieron vigentes durante siglos.
} 
mayo de 1492, la bula por la que se erigía en catedral la iglesia Mayor de Santa María de la Encarnación de Guadix. A ella se le aplicaron todas las posesiones, censos y rentas que tuvo la mezquita Mayor ${ }^{27}$.

El 20 de octubre de 1494 el viajero alemán Jerónimo Münzer visitó Guadix y su mezquita que, adaptada ya al culto cristiano, nos la describe de la siguiente manera:

Es su mezquita bastante bella, y hexagonal. Tiene setenta columnas libres, y en el centro un bello jardín cubierto, en medio del cual hay una fuente viva para sus acostumbradas abluciones. Ahora está dedicada a la bienaventurada Virgen María. Tiene obispo y doce canónigos, que viven de las rentas que antes tenía la mezquita en tiempos de los sarracenos $^{28}$.

Como verificamos en las palabras de Münzer, la catedral aprovechó en sus primeros años la fábrica de la mezquita con muy pocas variaciones. No será hasta 1496, una vez consolidada la conquista, cuando se pensó en transformarla en un auténtico templo cristiano. Por razones de economía de materiales, se aprovechó la misma disposición topográfica que venía impuesta por la mezquita. El mihrab fue aprovechado como puerta de acceso a la nueva catedral, mientras que sobre la nave se alzaría el cuerpo de la catedral. El resto de la mezquita (patio porticado y ajardinado) quedaría para la futura cabecera. Así fue surgiendo una catedral de planta basilical de tres naves y muy corta desde el presbiterio a la portada, con líneas góticas decadentes. Al frente de la dirección de su fábrica, Carlos Asenjo sitúa a Enrique Egas. Aquella iglesia gótica tenía una serie de capillas laterales, entre las que destacaba la de los marqueses de Diezma. La tierra de esta primitiva catedral estaba muy disputada para enterramiento de hidalgos, dividida en zonas con tarifas diferentes según la proximidad al altar mayor ${ }^{29}$. En torno al año 1500 se fueron adquiriendo o permutando las edificaciones que ocupaban la zona que habría de ser cabecera de la catedral, siempre, según Asenjo Sedano, siguiendo las trazas dadas por Enrique Egas. La financiación de la construcción de la nueva cabecera supuso un grave problema que hizo necesario solicitar a los hidalgos locales que fueran ellos los promotores de las capillas absidiales, mediante el derecho de enterramiento en ella y de privilegios litúrgicos para ellos y sus descendientes.

${ }^{27}$ Cf. Carlos Asenjo Sedano, La Catedral de Guadix (Guadix: Fundación Caja Rural, Cabildo de la Catedral de Guadix, 1977), 25-30.

${ }^{28}$ Jerónimo Münzer, Viaje por España y Portugal. Reino de Granada. Introducción de Manuel Espinar Moreno (Granada: Método, 2008), 108.

${ }^{29}$ Asenjo Sedano, La Catedral de Guadix..., 31-36. 
Los hidalgos más notables acudieron a tal llamamiento y así empezó a sacarse de cimientos la cabecera ${ }^{30}$. Sin embargo, no solo hombres acudieron a este llamamiento del Cabildo catedralicio. Según reflejan varios documentos que se custodian en el Archivo Histórico Diocesano de Guadix y que recoge y transcribe Carlos Asenjo en su obra Arquitectura religiosa y civil en la ciudad de Guadix en el siglo XVI, las mujeres también participaron junto a los hombres en la promoción y mecenazgo de la cabecera gótica de la catedral de Guadix ${ }^{31}$. Ejemplo de ello será el proceso constructivo de la conocida como capilla de Don Tadeo y en el que constataremos la presencia activa de varias mujeres.

En 1505 Quiteria del Castillo, mujer de Benito de Bitoria ${ }^{32}$, junto a sus hijos, Hernando del Castillo y Juan de Moreda, compraron al Cabildo una capilla conocida como del Sagrario por 24.000 maravedíes, con el fin de poder «hacer y edificar otra nueva capilla» y convertirla en enterramiento familiar. La primitiva capilla en la que, antes de su compra, fue enterrado Benito de Bitoria se situaba junto a la sacristía del templo gótico. Finalizado el proceso de compra, el Cabildo otorgó a Quiteria del Castillo y a sus hijos total libertad para edificarla de nuevo y colocar en ella sepulturas, bultos y las armas familiares. Además, se les concedió el altar frontal para que pudieran decir misa. En el documento de compra quedó establecido que si en un futuro esta capilla fuera derribada para construir la capilla mayor, la Iglesia estaría obligada a construir otra capilla similar a ésta ${ }^{33}$.

Corría el tiempo y a finales de la primera mitad del siglo XVI, la catedral gótica, terminada a medias, se mostraba insuficiente para albergar los cultos litúrgicos propios de la época; además corrían nuevos aires en la arquitectura. En 1549 Diego de Siloé se ocupa de las trazas y proyecta una nueva cabecera, torre y capilla redonda.

Quiteria del Castillo y sus hijos construirían a su costa aquella primitiva capilla de la que pocos datos más disponemos y que se mantendría en pie durante toda la primera mitad del siglo XVI, para, finalmente, caer víctima de la

${ }^{30}$ Ibidem, 37-38. El autor habla sólo de hombres, pero como veremos, las mujeres también serán promotoras y mecenas de estas capillas funerarias, contribuyendo con su economía y directrices a la construcción de un edificio público.

${ }^{31}$ Carlos Asenjo Sedano, Arquitectura religiosa y civil en la ciudad de Guadix en el siglo XVI (Granada: Universidad de Granada, 2000), 21-42. Apéndices 2, 8, 13 y 14 de esta obra.

${ }^{32}$ Respetamos la grafía original del documento en el que el apellido aparece con B. Benito de Bitoria (Vitoria), fue «contino» de los reyes. Censado como caballero, obtuvo la vecindad de Guadix por merced real, además de ello recibió 84 fanegas de tierra, aranzada y media de viña y un pedazo de carmen. Valorado todo en 36.000 maravedíes. Llegó a ser regidor de Guadix. Espinar Moreno et al. La ciudad de Guadix..., 127-136.

${ }^{33}$ Asenjo Sedano, Arquitectura religiosa y civil..., 21-23. Apéndice 2. 
nueva cabecera proyectada por Diego de Siloé en 1549. Tenemos constancia de que en 1565 la capilla ya no existía. En ese año Pedro Benavides de Castro, regidor de Guadix y heredero de la capilla que fue de sus abuelos, solicitó al Cabildo que se le entregara otra ya que en la antigua se había construido un zaguán, una escalera para subir al cabildo y se había colocado la puerta de tránsito al cementerio ${ }^{34}$. El Cabildo probablemente asignaría a los herederos otra capilla, ya que en 1597 el propietario y sucesor de Benito de Bitoria era Tadeo de Benavides y Cárdenas. Este año mismo año, el Cabildo de la Catedral solicitó al nuevo propietario que reparase la capilla que se encontraba en un estado ruinoso. Tenía al aire todo el techo y caídas y podridas todas las maderas. Se estimó en 500 ducados el gasto necesario para su reparación y puesta en servicio para la celebración en ella de los oficios religiosos. En caso de que el propietario no se hiciera cargo de su reparación, se le despojaría de cualquier derecho sobre ella y los cuerpos que había enterrados se vaciarían y serían trasladados a otra parte. Sin embargo, en esta fecha Tadeo de Benavides, no era el único propietario de la misma ${ }^{35}$. Eran herederas y propietarias también Marina de Luxán y Ana del Castillo. A ellas exigió también el Cabildo y el propio Tadeo de Benavides que, como herederas de Benito de Bitoria, arreglaran y repararan la capilla como era su obligación ${ }^{36}$.

No es nuestro objetivo detallar la historia de la catedral de Guadix, pues ya está ampliamente estudiada -aunque convendría dar un nuevo enfoque a estos estudios aplicando la perspectiva de género- sino el constatar cómo las mujeres estuvieron presentes en su construcción ${ }^{37}$. Para ello nos hemos centrado en una capilla, la conocida como de Don Tadeo, en la cual y a modo de cata arqueológica, hemos documentado la presencia activa en su construcción y reparo de varias mujeres a lo largo del siglo XVI. La primera, Quiteria del Castillo, que como viuda compró la propiedad y que se convirtió en promotora

${ }^{34}$ Ibidem, 34. Apéndice 8.

${ }^{35}$ Esta capilla era la conocida como capilla de Don Tadeo y se situaba en la primitiva catedral gótica entrando a la derecha, a la altura del coro. Tradicionalmente se ha mantenido que correspondía con la actual capilla de San Torcuato, hecho que es incorrecto pues ambas se situaban en extremos opuestos de la catedral.

${ }^{36}$ Asenjo Sedano, Arquitectura religiosa y civil..., 40-41. Apéndices 13 y 14. José Manuel Gómez-Moreno Calera, «Diversas precisiones sobre la catedral de Guadix y su ampliación barroca», Cuadernos de Arte de la Universidad de Granada 40 (2009): 224.

${ }^{37}$ La catedral de Guadix, está ampliamente estudiada desde varias perspectivas en la obra: Antonio Fajardo Ruiz, coord., La Catedral de Guadix. Magna Splendore (Granada: Mouliaá, 2007). También resultan de gran utilidad los artículos de Gómez-Moreno Calera, «Diversas precisiones sobre la catedral de Guadix...». Íd, «La Catedral de Guadix en los siglos XVI y XVII», Cuadernos de Arte de la Universidad de Granada 18 (1987): 107-118. 
junto a sus hijos de su construcción, con el fin de convertirla en enterramiento familiar. Con el paso de los años observamos cómo la edificación se va deteriorando hasta el punto de amenazar ruina. Es entonces cuando advertimos cómo los sucesores, hombres y mujeres, sin distinción de género, que heredaban la propiedad, heredaban también la obligación de mantenerla y repararla con sus propios bienes. Es en este momento cuando aparecen los nombres de Marina de Luxán y Ana del Castillo que, como herederas de la propiedad, tenían la obligación de costear su mantenimiento.

\subsection{Promotoras en la iglesia del convento de San Francisco}

Los franciscanos se establecieron en la ciudad de Guadix por virtud de una real cédula dada por los Reyes Católicos en la Vega de Granada el 25 de noviembre de $1491^{38}$. Inicialmente se instalaron en el sector llamado Sened hasta que se les asignó una zona de huertos extramuros y hacia el este de la ciudad. Ubicados en este nuevo emplazamiento, pronto comenzarán la edificación de su casa convento, a la que enseguida agregarían el proyecto de iglesia. La construcción de ambos abarca fundamentalmente toda la primera mitad del siglo XVI, aunque la finalización de la edificación se alargaría durante todo el siglo XVI. A los franciscanos les tocó en suerte el estamento aristocrático de la ciudad, por lo que la nobleza y los hidalgos asentados en Guadix hicieron del convento de San Francisco su centro religioso por excelencia.

Actualmente la iglesia consta de una nave rectangular central que constituye el templo. El presbiterio se sitúa en el cabecero de la nave un poco más alto, separándose de la nave central por un gran arco ojival sin apoyo de columnas o pilastras. En los laterales se abren capillas de profundidad variable ${ }^{39}$. Según Gómez-Moreno Calera podríamos estar hablando de la primera iglesia de Guadix y una de las más antiguas de la provincia. Su construcción supuso el despegue del mudéjar granadino. Inicialmente debió contar con sólo una nave principal, para añadirle sucesivamente la capilla mayor y otras varias laterales hasta alcanzar la configuración actual. A lo largo del siglo XVI y el siguiente algunas de las principales familias accitanas fundaron en ella diversa capillas y altares, ganando en prestigio y riqueza artística. La construcción de las capillas no corresponde a un plan inicial regular en su distribución, salvo

${ }^{38}$ Pedro Suárez, Historia de el Obispado de Guadix y Baza (Madrid: Imprenta de Antonio Román, 1696), 179. Alonso de Torres sitúa su fundación el 22 de diciembre de 1490. Transcurrido un año sin haberse edificado, los reyes expidieron la real cédula que se cita. Alonso de Torres, Chrónica de la Santa Provincia de Granada de la regular observancia de nuestro seráfico padre san Francisco (Madrid: Juan García Infançón, impresor, 1683), 91.

${ }^{39}$ Asenjo Sedano, Arquitectura religiosa y civil..., 135-140. 
las dos que se encuentran anexas al arco toral y que presentan sendos arcos apuntados de similar factura y amplitud. Las restantes, todas las del lado izquierdo, presentan arcos con distinta altura y anchura, lo que hace sospechar que se trata de realizaciones sucesivas. Este mismo lateral debió de contar incluso con más capillas cuyos arcos se encuentran hoy cegados bajo el coro ${ }^{40}$.

El estamento nobiliario que, como señalábamos con anterioridad, convirtió la iglesia del convento de San Francisco en su centro religioso, también fue el promotor y mecenas de gran parte de ella; sin olvidar que ese estrato estuvo formado por hombres y por mujeres. Ambos, aunque con atribuciones y roles distintos, componían esa parte de la sociedad llamada nobleza. Es por ello que ambos quisieron o estaban obligados a ensalzar y perpetuar la memoria de su linaje y qué mejor forma de hacerlo que promoviendo arquitectura religiosa. Es en esta función de promoción y mecenazgo en la que hemos podido documentar la presencia de dos mujeres que intervienen en la construcción de la iglesia de San Francisco. Se trata de María de Atouguía e Isabel de Luján, a cuyas figuras nos acercaremos más detenidamente en las siguientes líneas. Sin embargo cabe destacar que, si bien ellas son las más representativas, hubo otras mujeres que se citarán más adelante que también contribuyeron a la construcción o reparo de este templo.

\subsubsection{María de Atouguía, el mecenazgo de una lusitana en Guadix}

Doña María de Atouguía fue dama de la reina Isabel la Católica e hija de Mosén Lope de Atouguía; ilustre caballero portugués, montero mayor del rey Fernando, criado del rey de Castilla y comendador de Malagón ${ }^{41}$. Contrajo matrimonio con Francisco Pérez de Barradas, perteneciente a uno de los más importantes linajes del Reino de Granada, gozando desde un primer momento de una indiscutible posición social. Este caballero de ascendencia portuguesa fue conquistador del Reino de Granada, caballero de Santiago, capitán de la Reina y regidor de Guadix desde 1508. Obtuvo del repartimiento de la ciudad unas propiedades sobre las que edificó su palacio, situado en la Puerta Alta junto a la Alcazaba y una suerte de tierras. En 1531, el matrimonio formado por María de Atouguía y Francisco Pérez de Barradas vinculó sus bienes en mayorazgo a favor de su hijo Francisco; regidor de Guadix, paje del rey Católico y caballero de Santiago, que casó con doña Leonor de Figueroa ${ }^{42}$.

\footnotetext{
${ }^{40}$ Gómez-Moreno Calera, Arquitectura Mudéjar...., 112-114.

${ }^{41}$ Salvatore Leonardi, «De Portugal a Guadix pasando por Murcia. Datos para la historia de los primeros Barradas», Murgetana, $\mathrm{n}^{\circ} 114$ (2006): 84.

${ }^{42}$ Enrique Soria Mesa, Linajes granadinos (Granada: Diputación Provincial, 2008), 57-58. Juan
} 
El palacio de los Pérez de Barradas se situaba sobre la llamada Puerta Alta, Bib Rambla en época musulmana, en un espacio urbano que antes de la conquista cristiana de la ciudad se incluía en el recinto de la Alcazaba. Este espacio se segregó del recinto de la fortaleza. Se trata del primer palacio con estructura de castillo que se construye en la ciudad, apoyando su lateral oriental en las torres preexistentes. Su fachada entre torres, su sensación de macicez, su sobriedad externa y su escueta heráldica testimonian su datación en el primer tercio del siglo XVI ${ }^{43}$.

Francisco Pérez de Barradas y María de Atouguía, participaron de forma activa en el proceso de evangelización y castellanización que sufre la ciudad de Guadix tras la conquista cristiana. Ejemplo de ello es que contribuyeron a la fundación del convento de San Francisco de Guadix, constituyéndose como patronos y mecenas de la capilla mayor de su iglesia. Constancia de ello dejará María de Atouguía en su testamento en el que mandó que su cuerpo fuera sepultado «en la capilla major que mi marido Francisco Pérez de Barradas e yo emos edificado y hecho para este fin». Y donde deja claro que la capilla «es mía y della somos patronos mi señor Francisco Pérez de Barradas e yo e todas nuestros subcesores». La obra de la capilla fue iniciada a principios del siglo XVI y en 1528, Francisco Pérez de Barradas destinó para su remate 40.000 maravedíes anuales. Por su parte, María de Atouguía en su testamento, fechado el 4 de noviembre de 1552, destinó 300 ducados para la realización de un retablo e hizo donación de una serie de piezas de orfebrería y ornamento para los oficios religiosos ${ }^{44}$.

Tradicionalmente la figura de esta mujer portuguesa que fue dama de la reina, que desarrolló parte de su vida en la recién conquistada ciudad de Guadix y que contribuyó a su trasformación en ciudad cristiana, ha quedado relegada al olvido; pese a que, como hemos evidenciado, fue patrona, fundadora y mecenas en la iglesia de este convento. Prueba de la invisibilización a la que fue sometida esta mujer a lo largo de la historia la encontramos en la obra que en el siglo XVII escribió Alonso de Torres denominada Crónica de la Santa Provincia de Granada. En ella relata cómo los Reyes Católicos hicieron donación de esta capilla mayor a Francisco Pérez de Barradas y a su hijo don Lope de Figueroa en compensación por su participación en la conquista del reino. Obviando totalmente la presencia de María de Atouguía. Sin embargo,

de Hariza, Descripción genealógica de los excelentísimos señores marqueses de Peñaflor (Écija: Imprenta de Benito Daza, 1772), 2-4.

${ }^{43}$ Asenjo Sedano, Arquitectura religiosa y civil..., 263.

${ }^{44}$ El testamento de María de Atouguía se encuentra en el Archivo Municipal de Écija: L. 332, D. 12. Los fragmentos citados están recogidos en Leonardi, «De Portugal a Guadix...», 90. 
esta obra es interesante porque describe cómo era aquella capilla que costeó el matrimonio Pérez de Barradas-Atouguía. Según la crónica de Alonso de Torres, en el lado del Evangelio del altar mayor estaba situada la estatua de Francisco Pérez de Barradas armado y sobre la pared había pintada una batalla en la que constaba el siguiente texto:

Año de mil quatrocientos y noventa, Francisco Pérez de Barradas, trinchante del Rey Católico y su capitán, alcayde de la villa de La Peza, día de Santiago, con ocho de a cauallo y dos peones peleó con quarenta y dos moros de a cauallo y los venció y murieron veinte y seis de los moros.

En el lado de la Epístola, el cronista nos sitúa la estatua de su hijo Lope de Figueroa y Barradas. Bajo el altar mayor se encontraba una bóveda a la que se accedía por una escalera y en la que sobre un poyo se disponían los ataúdes ${ }^{45}$.

\subsubsection{Isabel de Luján, mecenas de arquitectura mudéjar}

Pocos datos biográficos hemos obtenido de doña Isabel de Luján. Las noticias que poseemos sobre su vida las conocemos a través de documentos relativos a la de su marido. Sin embargo, lo que sí conservamos de ella es un documento de valor incalculable para esta investigación: un contrato de obras firmado de su puño y letra, que analizaremos más adelante, y que nos ha permitido señalar a Isabel de Luján como una importante mecenas de arquitectura religiosa en la ciudad de Guadix.

Conocemos que Isabel de Luján fue la segunda esposa de Diego de Luján. Puesto que ambos compartían apellido, es muy probablemente que el matrimonio tuviera un importante grado de consanguinidad. Diego de Luján era sobrino de Constanza de Luján y de Fernando de Mendoza ${ }^{46}$, padres de Pedro de Mendoza y Luján, fundador de la ciudad de Buenos Aires y adelantado del Río de la Plata ${ }^{47}$. Por todo ello resulta evidente que Isabel de Luján perteneció a una de las familias más importantes de las asentadas en el Reino de Granada.

El linaje de los Luján (o Luxán) es originario de una aldea del mismo nombre, sita en las serranías de Muro de Roda, en Aragón. La casa-solar de

${ }^{45}$ Torres, Chrónica de la Santa Provincia de Granada..., 91-92.

${ }^{46}$ En los textos consultados aparece que este señor se llamaba Fernando, sin embargo en la documentación que hemos consultado aparece citado como Bernardo de Mendoza. Hemos mantenido el nombre con el que tradicionalmente se conoce a este caballero.

${ }^{47}$ Archivo Histórico Diocesano de Guadix [AHDGu]. C. 2780, D. 3. Fernando de Mendoza y Constanza de Luján fueron patrones y mecenas de la capilla mayor de la iglesia del convento de Santo Domingo, donde hoy en día perduran sus escudos. 
la familia estaba en Tierrantona, población de la comarca de Sobrarbe, en el valle oscense de La Fueva. Allí se erigía su castillo principal. El linaje terminó vinculándose de manera íntima con los Mur. Se crea entonces una nueva familia conocida como los Mur-Luján -o meramente Luján-, que en las siguientes décadas se dividiría en cuatro grandes ramas: los Lujanes de Madrid, con Miguel Jiménez de Luján como antepasado común; los de Cuenca, descendientes de un abuelo de Fernán García de Luján, que se instaló en Enguídanos a mediados del siglo XIV; los de Lérida y los Lujanes de Zaragoza. Pasado el tiempo personas de estas ramificaciones del linaje se diseminarían por la península y en especial por tierras conquenses, albaceteñas y andaluzas ${ }^{48}$. Todo parece indicar que los Lujanes accitanos provienen de la rama madrileña de este linaje.

Diego de Luján falleció en 1528 dejando viuda y sin hijos a su esposa Isabel de Luján. El matrimonio era poseedor de una capilla en la iglesia del convento de San Francisco de Guadix. Es por ello que Diego de Luján en su testamento ordenó que su cuerpo fuera sepultado en ella y que se sacasen de sus bienes 10.000 maravedíes y doce fanegas de trigo para fundar una capellanía sobre esta capilla. En ella se debían decir varias misas por su alma, la de su primera mujer, Quiteria, y la de sus padres y abuelos. Deja como patrona de la capellanía hasta el fin de sus días a su esposa, Isabel de Luján. Tras el fallecimiento de ésta, estipuló que la titularidad de la capellanía pasaría a Pedro de Mendoza y Luján, su primo ${ }^{49}$.

Conviene en este punto precisar que la capellanía era una fundación perpetua por la cual una persona segregaba de su patrimonio ciertos bienes, en vida o por testamento, y formaba con ellos un vínculo destinado a la manutención y sustento de un clérigo o institución, quedando obligado el titular a decir ciertas misas y oficios por las intenciones del fundador. El fundador de la capellanía regulaba normalmente en el documento originario todas las características de la fundación, desde su mismo objeto, al derecho de nombrar el beneficiario o beneficiarios de la misma, indicando, en ocasiones, hasta la clase de las misas u oficios a celebrar ${ }^{50}$.

${ }^{48}$ Cf. Óscar López Gómez, «Tradición y supervivencia política en tiempos de los Reyes Católicos: Juan de Luján, regidor de Madrid, alcaide de Escalona, Gobernador de Elche», en Madrid: su pasado documental, dir. por Juan Carlos Galende Díaz y Susana Cabezas Fontanilla, coord. por Nicolás Ávila Seoane (Madrid: Universidad Complutense, 2015), 203-227.

${ }^{49}$ AHDGu. C. 3181, D. 1, fol. 708.

${ }^{50}$ Manuel González Ruiz, «Las capellanías españolas en su perspectiva histórica», Revista Española de Derecho Canónico (1950), 475-501. Rafael Marín López, «Notas histórico-diplomáticas sobre Capellanías y Cofradías en la Catedral de Granada», Cuadernos de Estudios Medievales y Ciencias y Técnicas Historiográficas, no 20 (1995): 67-68. 
En el caso que nos ocupa la patrona o beneficiaria de esta capellanía, Isabel de Luján, además de hacerse cargo de la gestión de todo lo relativo a la celebración de misas y aniversarios, se convirtió en promotora y mecenas de la capilla sobre la que constituyó la fundación. Conocemos que la capilla familiar de los Lujanes de la iglesia de San Francisco se encontraba a medio construir en 1530. En este momento solamente tenía finalizada la cripta para enterramientos (ya que los cuerpos parece que se encontraban ya depositados allí en esta fecha), y los muros, que estaban sin enlucir ${ }^{51}$. Es por esto que doña Isabel de Luján, ya viuda, tuvo que finalizar la obra de la capilla familiar con el fin de ponerla en servicio y cumplir con su obligación de beneficiaria de la capellanía instituida por su marido. Así completó la capilla con la construcción de una armadura ochavada, un altar, una reja y el solado de ladrillo de toda ella ${ }^{52}$.

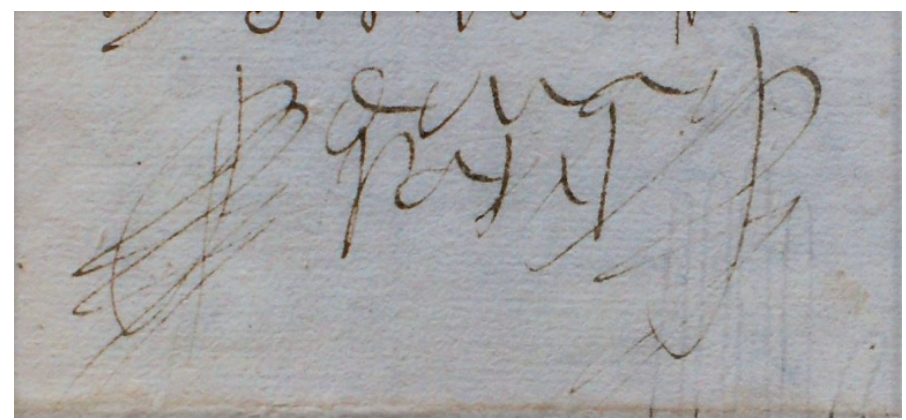

Fig. 1. Firma de Isabel de Luján en el contrato de obras para la ejecución de la capilla de San Francisco, 1530. AHPNGu, XVI, 9, fol. 186r. Se puede leer «doña Ysabel».

El 16 de agosto de 1530 doña Isabel de Luján y el carpintero Gaspar Ruiz firmaron el contrato para la ejecución de la capilla de Don Diego de Luján. El contrato se adjudicó, tras varios pregones públicos, a este carpintero por dieciséis mil trecientos maravedíes. Tras medir la capilla, Gaspar Ruiz recibió de Juan de Domedel ocho mil ciento cincuenta maravedíes, la mitad del precio por el que se adjudicó la construcción.

${ }^{51}$ Conocemos que en 1620 la capilla sobre la que Diego de Luján fundó una capellanía estaba dedicada al Cristo de Burgos. Hasta el momento no hemos podido ubicarla dentro de la iglesia, confiamos que en futuras investigaciones podamos hacerlo. AHDGu. C. 2780, D. 3.

${ }^{52}$ Archivo Histórico de Protocolos Notariales de Guadix [AHPNGu], XVI, 9, fols. 184v-186r. Si bien Carlos Asenjo recoge este documento en la página 141 de su obra Arquitectura religiosa y civil..., que hemos citado con anterioridad, nosotros hemos actualizado y corregido tanto su transcripción paleográfica y la signatura del mismo. 
Este es uno de los pocos contratos de obras en los que hemos documentado que una mujer, como promotora de la obra, lo firma con su nombre (fig.1.). El documento además contiene las prescripciones técnicas o condiciones que la señora estipuló para la finalización de la obra. Esto nos da una idea bastante aproximada del proyecto que ella patrocinó para el panteón familiar y con el que perpetuaría y ensalzaría su linaje y el de su familia.

La señora, como promotora y mecenas de esta nueva construcción, eligió una obra mudéjar. Según Gómez Moreno Calera, la arquitectura y, sobre todo, la carpintería mudéjar, con su repertorio de fantasía cromática y complejidad visual, representaba un modelo de riqueza más evidente que las propias bóvedas góticas o renacentistas. Es por ello que las capillas de los promotores de alta alcurnia se cubrían con el mismo tipo de estructura que tenían en sus propios salones palatinos ${ }^{53}$. Siguiendo esta tradición Isabel de Luján eligió una armadura de lazo para su capilla. Las características con las que se debía hacer la armadura quedaron establecidas de la siguiente manera (figs. 2 y 3 ):

Primeramente, el maestro que esta dicha obra tomara, asentará vnos estrivos con sus cuadrales enbebidos en la pared por cima del papo del arco, de manera que no toque la armadura en el tejado alto. $Y$ abaxo destos estribos, se sentarán vna solera con su desván y que sea asentada altura de una chilla y llevará sus pechinas de bozinas. Y encima destos dichos estribos se sentarán los paños de lazo conforme a la muestra, muy bien clavados en los estribos y las <chi>llas que hazen entre lazo y lazo yrá guarnecido de cinta saetín y luego será entretablada de sus tablas de pino y después de entablada se echará vna capa de yeso. Toda esta madera será de Güéscar y muy buena ${ }^{54}$.

En general, los carpinteros contrataban solamente la ejecución física de la techumbre y sus herramientas y el promotor debía poner los materiales. La madera con la que se elaboraban estas techumbres en Guadix era principalmente, como refleja el contrato de obras, de pino de Huéscar o de $\mathrm{Baza}^{55}$. Tanto los modelos de las cubiertas y techumbres como los propios carpinteros eran de fuera y llegaron a la ciudad junto con los repobladores. Eran tanto cristianos viejos como mudéjares o moriscos. Es por ello que desconocemos la procedencia del carpintero Gaspar Ruiz, adjudicatario de este contrato. En cuanto a su tipología, la armadura elegida por la promotora para cubrir un espacio posiblemente rectangular era una armadura ochavada, que suele ser la

\footnotetext{
${ }^{53}$ Cf. José Manuel Gómez-Moreno Calera, Arquitectura Mudéjar...., 35.

${ }^{54}$ AHPNGu, XVI, 9, fol. 185r.

${ }^{55}$ Gómez-Moreno Calera, Arquitectura Mudéjar..., 56.
} 


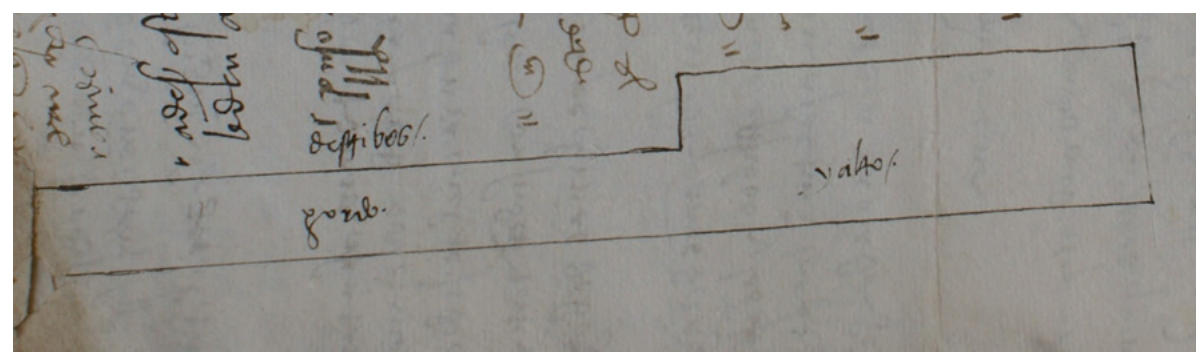

Fig. 2. Dibujo realizado en el margen izquierdo del contrato de obras para explicar cómo debían ser los estribos de la armadura, 1530. AHPNGu, XVI, 9, fol. 185v.

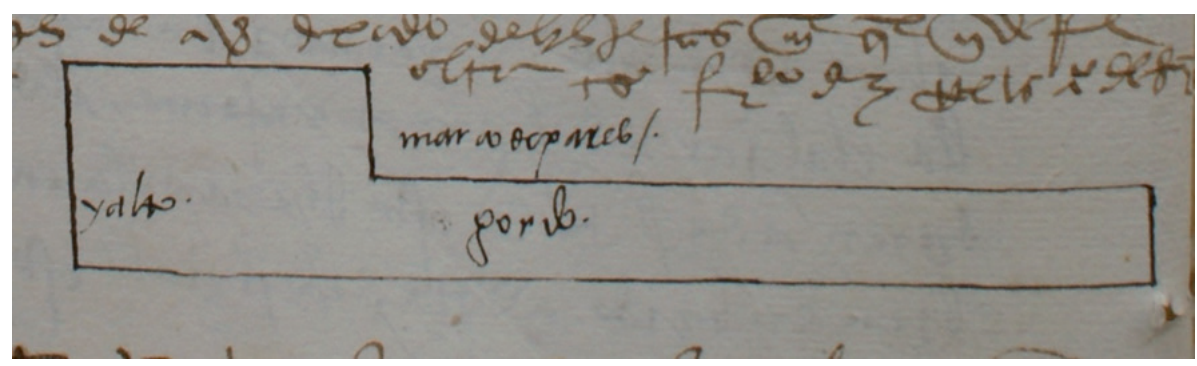

Fig. 3. Dibujo realizado en la parte inferior del contrato que explica cómo debían ser los marcos de pares, 1530. AHPNGu, XVI, 9, fol. 185v.

más ostentosa y ornamental. En la arquitectura religiosa se usó principalmente para cubrir capillas mayores. Están configuradas por ocho faldones y un almizate octogonal. Todas ellas son de limas moamares o dobles limas en los quiebros de cada paño ${ }^{56}$. La mayoría de estas armaduras solía estar policromadas, aunque en nuestro caso el documento no lo especifica. Quizá esto sea debido a que la policromía de la armadura sería objeto de un contrato diferente con un pintor. Dado que la armadura de la nave central de esta iglesia y la de la capilla mayor están policromadas, creemos que la de esta capilla también lo estuvo.

Como apuntábamos anteriormente, la armadura ochavada era propia de las capillas mayores, sin embargo, en el caso de la ciudad de Guadix, encontramos dos excepciones a ello en dos capillas laterales de dos iglesias conventuales. La primera excepción la hallamos en la armadura del proyecto de Isabel de Luján en la iglesia del convento de San Francisco que estamos analizando. La otra, en la armadura de la antigua capilla del Rosario de la iglesia conventual de Santo Domingo (fig. 4). Se trata esta última de una capilla pequeña, situada a la izquierda del arco toral de la iglesia y que, según Gómez Moreno Calera, debió construirse en la primera mitad del siglo XVI, antes de 1563. La armadura de esta capilla constituye una pieza excepcional del mudéjar accitano.

${ }^{56}$ Ibidem, 62. 
Su forma es ochavada, cuajada de lazo de diez y con una policromía delicada que refuerza sus líneas geométricas ${ }^{57}$. Dado que el proyecto de nuestro estudio está fechado en 1530, es muy probable que la armadura financiada por Isabel de Luján sea anterior a la de la capilla de la iglesia de Santo Domingo. Quizá podría haber sido precedente de ella y estar ambas estrechamente vinculadas; más aún si tenemos en cuenta que Isabel de Luján estaría emparentada con Constanza de Luján, mecenas, junto a su marido, de la capilla mayor de la iglesia de Santo Domingo. Este extremo no podemos confirmarlo al no existir hoy en día rastros del proyecto de Isabel de Luján.

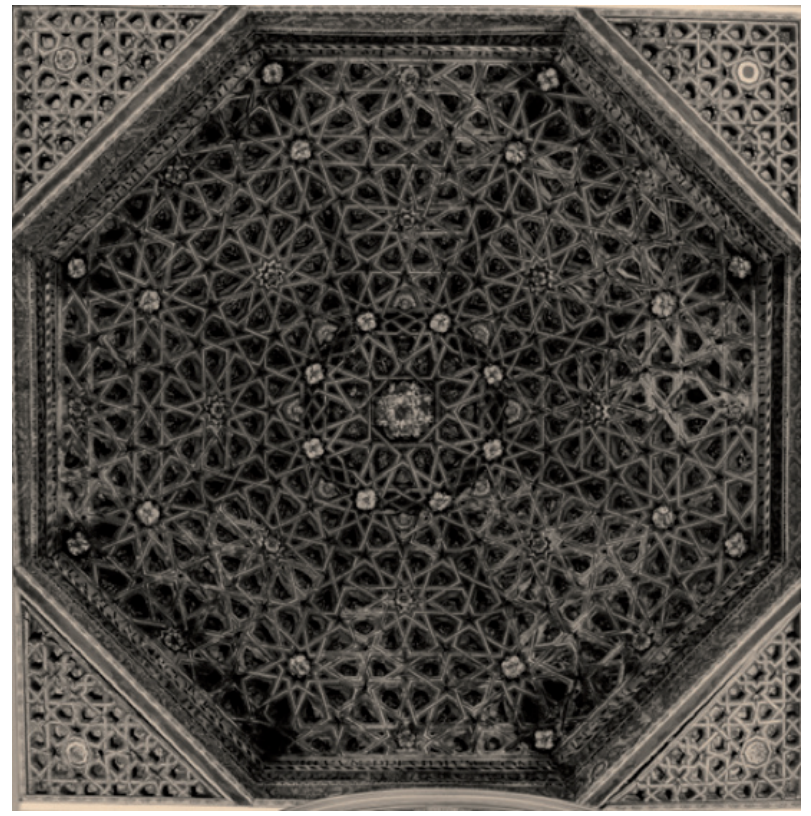

Fig. 4. Armadura ochavada de la antigua Capilla del Rosario. Iglesia conventual de Santo Domingo, Guadix (Granada). Primera mitad del siglo XVI.

Podemos saber que la capilla de Isabel de Luján estaba separada de la nave central por un arco apuntado, que es el que aparece sistemáticamente en los templos más antiguos de Guadix, tanto para los arcos torales como para las capillas laterales. Hoy en día persiste este tipo de arco en las capillas laterales de la iglesia de San Francisco ${ }^{58}$. Tras el arco, la planta rectangular que conformaría la capilla se cubriría con la armadura descrita. Además de esto el

\footnotetext{
${ }^{57}$ Ibid., 109.

${ }^{58}$ Ibid., 44.
} 
proyecto contempló que el espacio quedaría aislado dentro de la propia iglesia y formando un espacio privado tras la instalación de una reja. La señora dio las indicaciones para su construcción:

A se de hazer vna rexa en esta dicha capilla con dos medias puertas, que vaya de sus verjas quadradas, con vn verdugo por las esquynas y los travesaños que atraviesan vayan de sus molduras. Y que lleve su solera por baxo, a rayz del solado, y que lleve un coronamiento labrado de talla ${ }^{59}$.

El contrato no precisa si la reja debía ser de madera o de hierro. Sin embargo y dado que el contrato fue adjudicado a un carpintero y que contemplaba que el coronamiento de la misma debía ir labrado de talla, entendemos que se refiere a una reja de madera. El plan contemplaba también el solado de la capilla que debía ser «de ladrillo rascado y de junto, cerrado», es decir un ladrillo colocado sin apenas mortero entre hilada e hilada, lo que le daría una terminación más refinada ${ }^{60}$.

La obra de la capilla se completaría con la construcción de un altar que debía tener las siguientes especificaciones:

que vaya con su peana, con vna grada y solado y asymismo y que por el arista de la grada de la peana vaya una hilada de aliçares verdes y vaya enluzida la frontera de la grada con toda la capilla. El altar a de ser güeco conforme al de santa Ana y al tamaño que se lo pidiere ${ }^{6 l}$.

El hecho de que se especifique que el altar debía de ser hueco, nos podría indicar que estaría preparado para la posterior contratación y colocación de un retablo. Destacamos en esta obra la presencia de la cerámica decorativa, frecuente del mudéjar y que está presente en los alizares vidriados en verde del altar. Finalmente toda la capilla debía de ser enlucida sobre su jaharro ${ }^{62}$. En el pasado, el interior de los templos se enlucía y revocaba -con su costra de mezcla fina y blanqueado- para protegerlos y darles una vista más armoniosa y decente ${ }^{63}$.

${ }^{59}$ AHPNGu, XVI, 9, fol. 185r.

${ }^{60}$ Gómez-Moreno Calera, Arquitectura Mudéjar..., 42. Jean Passini documenta el uso de este tipo de ladrillo, conocido como ladrillo rascado, en varias casas de Toledo a inicios de la segunda mitad del siglo XV. Jean Passini, Casas y casas principales urbanas. El espacio doméstico de Toledo a fines de la Edad Media (Toledo: Universidad de Castilla-La Mancha, 2004), 50-74.

${ }^{61}$ AHPNGu, XVI, 9, fol. 185r.

${ }^{62}$ Ibidem.

${ }^{63}$ Gómez-Moreno Calera, Arquitectura Mudéjar..., 56. 
Lamentablemente no ha llegado hasta nosotros ningún elemento original de los que describimos de esta capilla. Tampoco conocemos su ubicación exacta dentro de la iglesia, aunque como señalábamos con anterioridad, debió de estar muy próxima, o incluso pegada, a la capilla mayor. Nos aventuramos a pensar que se situaría en el lado derecho del arco toral ${ }^{64}$.

La existencia de este contrato de obras firmado por una mujer, así como otros ejemplos de mecenazgo femenino que hemos podido documentar en Guadix y Granada, nos hace afirmar que el contrato que analizamos de Isabel de Luján era sólo una fase de un plan más ambicioso que culminaría con la decoración y dotación de todo lo necesario para la puesta en servicio de esta capilla. Esto la convierte en una mecenas en el más amplio sentido de la palabra, así como en impulsora y responsable, junto a María de Atouguía y otras mujeres y hombres, de la construcción y conformación de la iglesia de San Francisco de Guadix.

Hemos documentado así de manera inequívoca cómo en el siglo XVI las mujeres no sólo daban las directrices, más o menos detalladas, de cómo querían que fueran sus proyectos sino que evidenciamos que algunas de ellas tenían conocimientos técnicos de arquitectura. Ejemplo de ello es el que nos las encontremos firmando contratos de obras o estipulando -como el caso de Isabel de Luján- qué tipo de armadura se debía construir en su capilla. Una armadura que podemos enmarcar junto al resto de la obra dentro del mudéjar accitano. Esto convierte a Isabel de Luján en la primera mujer, de la que se tiene constancia hasta la fecha, mecenas de arquitectura mudéjar en la ciudad de Guadix y derriba el tópico de que la arquitectura es algo pensado sólo por hombres ${ }^{65}$.

\subsection{Ana Félix de Guzmán, marquesa de Camarasa, y el Colegio de los jesui- tas de Guadix}

Ana Félix de Guzmán fue hija de Francisca de Ribera Niño y de Pedro de Guzmán y Zúñiga, I conde de Olivares, y nieta del duque de Medina Sidonia ${ }^{66}$.

${ }^{64}$ Documentamos más adelante cómo la capilla situada a la izquierda del arco toral perteneció al matrimonio formado por Isabel de Benavides y Rui Pérez de la Cueva, es por esto que planteamos que la capilla de los Lujanes fuera la situada a la derecha.

${ }^{65}$ Hemos documentado el caso de otras mujeres que ejercen las labores de mecenazgo y promoción arquitectónica en Guadix. Sin embargo, en el caso de Isabel de Luján, el hecho de que ella lleve a cabo este proyecto arquitectónico sola, sin la presencia de su marido, y las especificaciones técnicas que conocemos del mismo, nos ha permitido situarla como la primera mujer, de la que tenemos constancia fehaciente, que promueve arquitectura mudéjar en Guadix.

${ }^{66}$ Ginés de la Jara Torres Navarrete, Historia de Úbeda en sus documentos. Tomo II: Linajes y hombres ilustres (Úbeda: Asociación Cultural Ubetense «Alfredo Cazabán Laguna», 2005), 99-100. 
Era una de las dieciséis damas de la reina Isabel de Valois, permaneciendo a su servicio desde 1560 a 1567 (fig. 5). En la Corte se la conoció por la introducción de libros piadosos que contrarrestaban la influencia de los libros profanos, como los de caballería, a los que la reina era muy aficionada. El 14 de mayo de 1568 casó con Francisco Miguel de los Cobos y Luna, adelantado de Cazorla y conde de Ricla, hijo de Francisco de los Cobos, del consejo del emperador Carlos V. Francisco Miguel de los Cobos fue II marqués de Camarasa, caballero de Santiago, capitán de la Guardia Española, señor de Sabiote, Jimena, Recena, Torres y Canena desde 1594 a 1616. Según las crónicas de la época, con motivo de esta boda se celebraron grandes fiestas en el Alcázar de Madrid ${ }^{67}$.

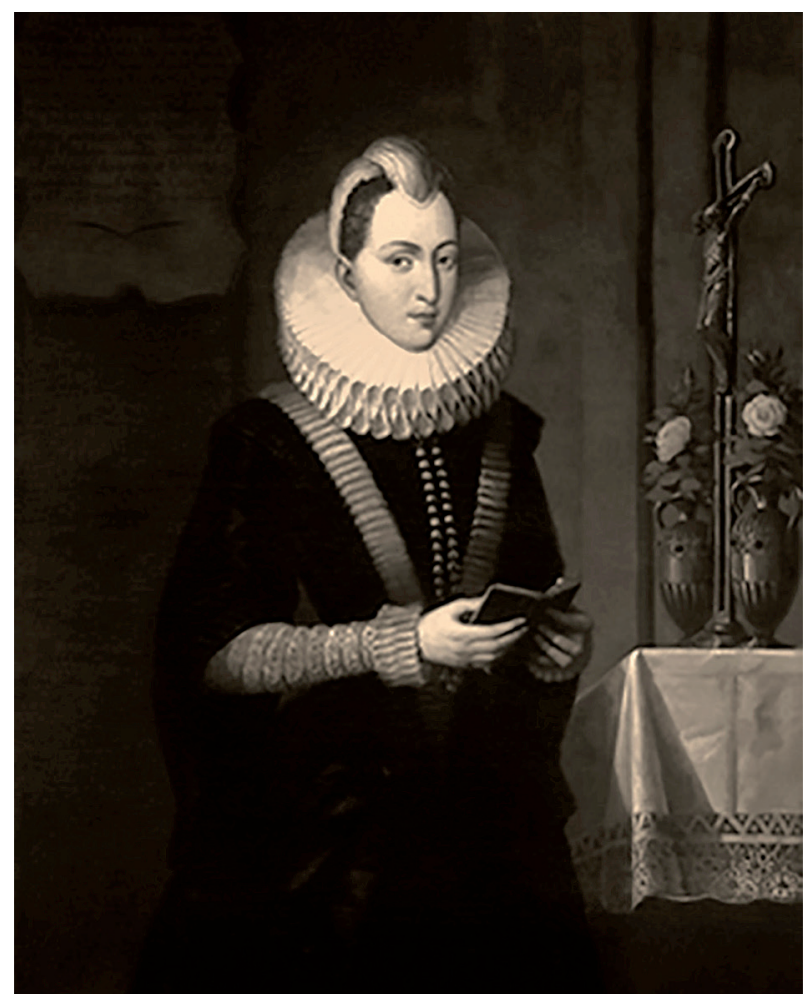

Fig. 5. Retrato de Ana Félix de Guzmán, marquesa de Camarasa. Ca. 1674. Fundación Casa Ducal de Medinaceli. [Disponible en http://www.fundacionmedinaceli.org/casaducal/fichaindividuo.aspx?id=1206, última consulta $28 \mathrm{de}$ mayo de 2020].

${ }^{67}$ Joaquín Gil Calvo, «La iglesia de San Ildefonso y la casa profesa de la Compañía de Jesús en Toledo», en Anales Toledanos, tomo VI, (Toledo: Diputación Provincial, Instituto Provincial de Investigaciones y Estudios Toledanos, 1973), 211. 
La marquesa de Camarasa gestionó un inmenso patrimonio. Muestra de ello es que en 1591 el marqués de Camarasa le otorgó un poder para que pudiera cobrar de sus juros y rentas 4.000 ducados anuales, asignados para el gasto de su cámara. Además de ello, el marqués estipuló para su esposa 20.600 ducados para sustento de su casa y familia. A esto habría que sumar 4.000 ducados más fijados para las necesidades de sus hijas doña Francisca y doña María, monjas en Santo Domingo el Real y el monasterio de las Descalzas de Madrid. Por tanto, la cantidad concedida a la marquesa por su marido ascendía a 70.000 ducados anuales. Esta asignación fue aprobada por una facultad real expedida por Felipe II el 4 de febrero de 1591 en Madrid. El 23 de junio de 1594, en Madrid, Francisco de los Cobos y Luna, ante el escribano Gaspar Cerecedo, otorgó a su mujer otro poder. Por él concedía a Ana Félix de Guzmán libertad para disponer, tanto en vida de él y como tras su muerte, de todos sus bienes y la facultaba para otorgar escrituras ${ }^{68}$. Este último poder conferiría a la marquesa total libertad de movimientos sin necesidad de estar sus actos supeditados a la aprobación de su marido.

Doña Ana Félix de Guzmán fue una mujer piadosa. Estuvo muy vinculada a la Compañía de Jesús. Es por ello que invirtió gran parte de su patrimonio en la fundación y construcción de varios conventos. En 1605 fundó el Noviciado de la Compañía de Jesús en Madrid, sito en la calle Ancha de San Bernardo, y al que dotó con tres mil ducados de renta anual. Al frente de él puso a su confesor, el jesuita Francisco de Robledillo. La primera misa se celebró en una pequeña iglesia dispuesta para ello el 30 de noviembre de 1602. Posteriormente, en 1606, se construyó una iglesia más grande dedicada a san Ignacio ${ }^{69}$. Además del colegio de Madrid, la marquesa fundó otro en la villa de Cazorla y un convento de carmelitas descalzas en Sabiote ${ }^{70}$. Sin embargo, como veremos, éstas no fueron las únicas instituciones promovidas por la marquesa de Camarasa. Fuera de sus dominios, en la ciudad de Guadix, llevará a cabo otra fundación que es el objeto de nuestro estudio ${ }^{71}$.

${ }^{68}$ Archivo Histórico Nacional [AHN]. Códices, L. 885, fols. 11r-12r.

${ }^{69}$ José Antonio Álvarez y Baena, Compendio de las grandezas de la coronada villa de Madrid (Madrid: Imprenta de don Antonio de la Sancha, 1786), 27.

${ }^{70}$ Joseph Antonio de Hebrera, Vida exemplar de la excelentísima señora y venerable madre sor María de las llagas, marquesa de Camarasa y fundadora del insigne y religiosísimo convento del Ángel de la Guarda de la ciudad de Granada de la primera regla de la seráfica madre santa Clara (Zaragoza: Domingo Gascón, impresor, 1698), 75.

${ }^{71}$ La información que a continuación presentamos relativa a la fundación del Colegio de San Torcuato de Guadix se encuentra recogida en: AHN. Códices, L. 885, fols. 1-38. 


\subsubsection{La fundación del Colegio de San Torcuato}

El 10 de septiembre de 1599, en Roma, el general de la Compañía de Jesús, Claudio Aquaviva aceptó de Ana Félix de Guzmán, marquesa de Camarasa, condesa de Ricla, señora de los estados de Cazorla y Sabiote, la dotación de 1538 ducados de renta anual que había hecho para que se fundase el Colegio de San Torcuato de Guadix, nombrándola así fundadora del mismo ${ }^{72}$. El 16 de abril de 1602, la marquesa de Camarasa, hizo escritura de fundación y patronazgo ante el padre Melchor de Gadea, provincial de Compañía en la provincia de Andalucía. En la escritura consta que, de sus limosnas y las de sus parientes a los que había pedido ayuda (como fue el duque de Medina Sidonia y la condesa de Santisteban que le había dado 1000 ducados) y con el poder que tenía de su marido para disponer de sus bienes y otorgar escrituras, aceptaba la fundación y patronato de este Colegio bajo una serie de condiciones. La primera de ellas fue que se la nombrara patrona y fundadora junto a su marido y, tras su fallecimiento, le sucediera en el patronato su hijo mayor. La segunda, que el Colegio debía contar con maestros de gramática que instruyeran a la juventud del obispado y con escuelas de primeras letras y doctrina cristiana para los niños. La tercera premisa establecía que a partir del año de 1603 se debían señalar 800 ducados de la renta anual para su fábrica. Estos ducados no podrían gastarse en otras cosas más que en comprar el sitio y edificar casa e iglesia. Estipula que hasta que los dos edificios no estuvieran finalizados, la Compañía no podía disponer de ellos libremente. Además de ello, también impuso que se gastaran 10 ducados anuales en rosarios, premios para los niños y estudiantes y 20 en libros; que los religiosos salieran a misiones por todo el obispado y su comarca, enseñando la doctrina cristiana, predicando y confesando a los fieles. Finalmente, en cuanto a que era fundación propia de la marquesa, el Colegio quedaba obligado a decir una serie de misas por la fundadora y, por devoción particular de la marquesa, se habría de decir una misa el día de la Encarnación y otra el de la Santísima Trinidad.

El 20 de septiembre de 1605, el general de la Orden le concedió a la fundadora el privilegio de que la misa mayor del día de la Encarnación de cada año se celebrase en honor de los marqueses, de sus hijos y de sus descendientes como ella había impuesto. Lo mismo se haría el día de la Trinidad y el de la confirmación de la Compañía. Ese año la marquesa ratificó la escritura de

${ }^{72}$ El 3 de abril de 1599, se expide la real provisión en la que manda que se erija el Colegio de San Torcuato. Manuel Quesada Martínez, «Los Jesuitas en Guadix y su comarca: de las primeras misiones a la fundación del Colegio», en Actas del I Coloquio de Historia "V Centenario de la entrada en Guadix de los Reyes Católicos (1489-1989)" (Guadix: Seminario de Historia del I. B. Padre Poveda, 1989), 157-162. 
donación, no sin antes dejar concretado en ella que los jesuitas debían dejarla poner las armas y escudos de los marqueses de Camarasa en el Colegio y en los lugares donde ella o sus sucesores quisieran. El 2 de diciembre de 1606, en un escrito de su puño y letra y al que acompaña la firma del hermano Cristóbal Velázquez, la marquesa declaraba que la donación asignada era de 20.000 ducados de renta anual, si bien en las escrituras de fundación constaban que fueron 1538 ducados $^{73}$. Es por esto que podemos señalar a Ana Félix de Guzmán como la fundadora y principal mecenas del Colegio jesuita de Guadix, al que asignó casi un tercio de las rentas anuales que estipuló su marido para ella; una auténtica fortuna que permitiría que la construcción del colegio y la iglesia avanzaran rápidamente.

El Colegio de los jesuitas y el templo anexo tuvieron una enorme influencia en la vida de la ciudad a través de su intervención en el culto de san Torcuato y san Fandila y a través de la educación que se impartía en sus clases a la mejor sociedad accitana ${ }^{74}$. En su escuela pública, según un acuerdo entre la Compañía y los Cabildos catedralicio y de la ciudad, se adoctrinaba a los niños, lo mismo en lo referente a leer y escribir como en lo referente a la doctrina cristiana ${ }^{75}$.

Conviene precisar que el asentamiento de los jesuitas en Guadix llegó de la mano del también jesuita y accitano Cristóbal Velázquez, al que citábamos antes. Durante su estancia en Madrid maduraría la idea de fundar un colegio de su Orden en su ciudad natal. Para conseguir los fondos necesarios, acudió a la marquesa de Camarasa que, como ya mencionamos, había dotado los de Madrid y Cazorla ${ }^{76}$. El padre Velázquez también recuperó para la fundación antiguas donaciones hechas por personas devotas. Este es el caso de las hermanas Calvache; Lucrecia, mujer del licenciado Solorzano, y Florencia, o la de Juan de Grijalba. Todos ellos donaron sus casas para que se emplazara en ellas el colegio $^{77}$. Las casas donadas a la Compañía se situaban en un solar intramuros, entre la catedral y la plaza de los Corregidores.

Tras la instalación de los jesuitas, la pequeña capilla donde celebraran eucaristía pronto se vio insuficiente por la incorporación de nuevos hermanos y el aumento de feligreses. Es por ello que iniciaron la obra de la iglesia, que

${ }^{73}$ AHN. Códices, L. 885, fols. 1-38.

${ }^{74}$ Asenjo Sedano, Arquitectura religiosa y civil..., 176.

${ }^{75}$ AHN. Códices, L. 885, fol. 30.

${ }^{76}$ Alberto y Arturo García Carraffa. Enciclopedia heráldica y genealógica hispano-americana. Diccionario heráldico y genealógico de apellidos españoles y americanos (Madrid: Imprenta de Antonio Marzo, 1920-1963), vol. XXVI, 7 y volumen XL, 156.

${ }^{77}$ Quesada Martínez, «Los jesuitas en Guadix... », 157-162. 
se finalizó en 1605. Esta iglesia también pronto quedó pequeña, por lo que se encargaron nuevas trazas al padre Pedro Sánchez arquitecto de la Orden. Tras algunas modificaciones al proyecto, se iniciarían las obras en 1622, dilatándose hasta entrado el siglo XVIII. La iglesia, diseñada en forma de T, con una amplia cabecera conformada por una cúpula en el transepto, dos brazos de crucero muy poco desarrollados, con hornacinas abiertas en el lateral del presbiterio y capilla mayor flanqueada por pequeñas hornacinas. La nave longitudinal no pudo continuarse más que con un tramo. Junto a la iglesia se construyó el colegio que se ordenaba en torno a un patio principal y otros secundarios $^{78}$.

La marquesa falleció en Madrid el 16 de junio de $1612^{79}$, por lo que no pudo ver, ni si quiera comenzada, la iglesia que describimos, si bien se construyó con parte de sus bienes. Pese a ello, la figura de Ana Félix de Guzmán, relegada al olvido de la historia accitana, fue clave para el desarrollo posterior de la ciudad. Una madrileña que apostó por invertir su patrimonio en Guadix y convertirse en mecenas de esta ciudad. Con su proyecto cambió la fisonomía de la ciudad y la dotó de una serie de servicios, religiosos y docentes, de los que antes carecía.

\subsection{María de Hurrutia y su intervención en el lugar de Paulenca}

María de Hurrutia y Belasco fue hija de Pedro de Hurrutia y Barguen y de Beatriz de Aguilar y Ponce ${ }^{80}$. Su padre era originario del lugar de Molinar, en el valle de Gordejuela, en el señorío de Vizcaya. Además de ella, el matrimonio tuvo otro hijo llamado Francisco de Hurrutia. Es muy probable que la familia se asentara en Guadix como repobladores tras la expulsión morisca. En Guadix, María de Hurrutia casó con Andrés de Cárdenas y Luján del que pocos datos más tenemos. El matrimonio, que no tuvo hijos, tenía su casa principal en la parroquia de la Iglesia Mayor. María de Hurrutia, viuda, falleció el veinte de marzo de 1642. Es en su testamento donde descubrimos todos los datos que aportamos a este estudio donde destaca el ingente patrimonio que gestionó al final de su vida ${ }^{81}$.

${ }^{78}$ Cf. José Manuel Rodríguez Domingo y Ana María Gómez Román, «El patrimonio artístico del Colegio de San Torcuato de Guadix, de la Compañía de Jesús», Boletín del Centro de Estudios Pedro Suárez, nº 12 (1999): 138-140.

${ }^{79}$ Jara Torres Navarrete, Historia de Úbeda..., 100.

${ }^{80}$ Se ha mantenido las grafías originales con las que aparece el nombre de esta señora en la documentación de archivo.

${ }^{81}$ AHDGu. C. 4006, D. 34. 
Entre los bienes que la señora poseyó en vida podemos citar: la casa principal de la parroquia de la Iglesia mayor, así como otras casas repartidas por la ciudad, dos cortijos en la vega de Guadix con sus casas, tinados y tierras, que llamaban Frontina y Meçina, y una venta situada en medio de ellos llamada Tejada. Estas propiedades rústicas lindaban con tierras del lugar de Fonelas, con el río Fardes, con el arroyo de Frontina y con el camino Real que iba a Úbeda. También era de su propiedad el lugar de Paulenca, que ella compró. Innumerables censos en términos como Lanteira, Fiñana, Abla y la propia ciudad de Guadix. Una capilla en la iglesia del convento de San Francisco, junto a la mayor y en el lado del evangelio, que heredó de sus padres. Un asiento y sepultura en la catedral, en el postel del agua bendita de la nave mayor, que compró de doña Clementina de Segura. Además de numerosas obras de arte que detallaremos más adelante. Según menciona en su testamento, era la propia María de Hurrutia quien administraba su hacienda, anotando en sus libros y papeles «todo quanto e recibido por todo lo que me an debido y deben ${ }^{82}$. La administración incluía el mantener en condiciones sus propiedades y su patrimonio. Así lo refleja el que a su costa reparara la capilla familiar del convento de San Francisco, al que legó en su testamento 800 ducados para su mantenimiento ${ }^{83}$. Sin embargo, María de Hurrutia no se limitó a conservar y reparar sus bienes, sino que los aumentó. Este es el caso de la compra que hizo del lugar de Paulenca con todo lo que a él pertenecía.

En la primera mitad del siglo XVI, Paulenca estaba adscrito a la jurisdicción de Guadix. Era un arrabal formado por cuevas de moriscos y con una iglesia pequeña con dos puertas, una de ellas orientada hacia la salida del sol. Por el escudo que hoy en día todavía se conserva en ella del obispo Antonio del Águila y Paz, podemos datarla entre 1537 y $1546^{84}$. Descripciones de la época, como las de los seises moriscos de 1571, describen el lugar como situado en una solana, en una ladera y bajo una torrontera. Formado por 40 casas y cuevas, de las que 3 casas eran de cristianos viejos. Tenía un horno y los vecinos iban a moler el grano a Guadix ${ }^{85}$.

Doña María de Hurrutia intervendrá arquitectónicamente en este lugar tras su adquisición que, después de la expulsión morisca, habría quedado desha-

${ }^{82}$ Ibidem, fol. $24 \mathrm{v}$.

${ }^{83}$ Ibidem, fols. 15-21.

${ }^{84}$ Carlos Asenjo Sedano, Episcopologio de la Iglesia Accitana (Guadix: Instituto de Estudios Pedro Suárez, 1990), 102.

${ }^{85}$ Manuel Espinar Moreno, «Los moriscos de Guadix y el Cenete en época de Carlos V», en Carlos V. Los moriscos y el Islam, coord. por María Jesús Rubiera Mata (Madrid: Sociedad Estatal para la Conmemoración de los centenarios de Felipe II y Carlos V, 2001), 127-149. 
bitado y abandonado, tanto el asentamiento como su iglesia. Es por eso que construyó a su costa varias casas y realizó importantes reparos en su iglesia, con el fin de volverla a adaptar al culto y que se volviera a decir misa para los labradores y las personas del lugar que no pudieran ir a oírla a Guadix ${ }^{86}$.

Recuperado el lugar, a su fallecimiento y según consta en su testamento, lo dejó al Colegio de la Compañía de Jesús para que con estos bienes pudieran «labrar iglesia y hacer vivienda para los religiosos» y dispuso que una vez finalizado todo ello, el Colegio tuviera estos bienes como propios ${ }^{87}$. Este hecho, desconocido hasta el momento, nos sitúa a la señora como una de las impulsoras, junto a la marquesa de Camarasa, de la construcción de la iglesia jesuita en Guadix. Hablamos en femenino porque, como hemos visto en el epígrafe dedicado a la marquesa, fueron varias las mujeres que junto con algunos hombres, hicieron posible que la Comunidad Jesuita se instalara en Guadix.

Volviendo a nuestra promotora, el lugar de Paulenca no fue lo único que doña María de Hurrutia legó a los jesuitas. Les dejará para los oficios religiosos varias piezas de valor, como un pomo de plata con un brasero de hierro, que debería servir en las fiestas, y cuatro candeleros de plata pequeños bujías que deberían servir en las fiestas del Santísimo Sacramento ${ }^{88}$.

\subsection{1. ¿Coleccionista de arte religioso?}

Como hemos podido observar María de Hurrutia fue una de las damas más principales del Guadix de la primera mitad del siglo XVII. Gestora de un gran patrimonio, fue también promotora y mecenas de arquitectura, tanto civil como religiosa. Pero además de ello, fue una gran «coleccionista» de obras de arte de tema religioso que custodiaba mayoritariamente en el oratorio de su casa principal. Conviene recordar que el oratorio doméstico fue un lugar honorable en las casas particulares, destinado al retiro, el recogimiento y la oración. Era el espacio en el cual, por privilegio, se celebraba el santo oficio de la misa. Igualmente, fue el cuarto de oración que montaron familias de la sociedad cuya capacidad económica se lo permitía. Las diferencias cualitativas entre los oratorios radicaban en el mobiliario y la cantidad de imágenes de culto que poseían. Un oratorio bien equipado tenía representaciones en lienzo y en lámina, estampas, esculturas de bulto, cajones con imágenes, así como algunos muebles, candeleros, pilas de agua ${ }^{89} .$. A juzgar por los elementos que

\footnotetext{
${ }^{86}$ AHDGu. C.4006, D. 34, fol. 17r.

${ }^{87}$ Ibidem, fol. $23 \mathrm{r}$.

${ }^{88}$ AHDGu. C. 4006, D. 34, fol. 5v.

${ }^{89}$ María del Pilar López Pérez de Bejarano, «El oratorio: espacio doméstico en la casa urbana de
} 
decoraban el oratorio de la señora, el suyo era bastante importante. Desconocemos si tenía licencia para celebrar misa. En tal caso el Sínodo de la diócesis de Guadix y de Baza de 1554 estableció «que no se digan misas privadas en casas particulares sino fuere en lugar muy decente, especial los días de fiesta de guardar y domingo $»^{90}$. Por tanto si María de Hurrutia tenía permiso para decir misa en su oratorio particular, no podría celebrarse los domingos y fiestas de guardar, quedando obligada esos días a asistir al culto en la iglesia Mayor, a cuya parroquia pertenecía.

Volviendo a la faceta de «coleccionista» de la señora, detallaremos a continuación las obras que, tras su muerte y procedentes en su mayoría del oratorio particular, dejó a diversas personas e instituciones religiosas accitanas. Uno de los grandes beneficiados del patrimonio tanto económico como artístico de la señora, como señalábamos, fue el Colegio de la Compañía de Jesús ${ }^{91}$. A esta institución legó, para adorno de la iglesia y asistencia de los religiosos, las siguientes obras: Un cuadro de san Atanasio, guarnecido, para que se colocara en una capilla de la iglesia. Un cuadro de santa Luparia, otro cuadro del santo Cristo en el sepulcro y seis láminas. Además de ello, un san Juan Bautista de bulto procedente también de su oratorio.

A Mariana de la Cueva y Benavides dejó cuatro láminas de las que estaban en su oratorio, un cuadro sin lienzo que estaba colocado en la escalera de su casa, un cuadro grande de san Jerónimo y otro de san Juan Bautista ${ }^{92}$.

A Clara de Benavides, monja en el convento de Santiago, dejó para su celda, un cuadro de Nuestra Señora sentada al pie de una oliva con el Niño en brazos y san Juan debajo. Estipulando que al final de los días de esta monja, se hiciera en el coro del convento un nicho donde quedara el cuadro para siempre. Además de ello, legó a la Comunidad un Niño Jesús de bulto que tenía en su oratorio.

El otro gran beneficiado del testamento de doña María de Hurrutia fue el convento de la Concepción, al que dejó gran número obras. El lote asignado estaba compuesto por un cuadro del Desconsuelo de Nuestra Señora, para el

Santa Fe durante los siglos XVII y XVII». Ensayos. Historia y Teoría del Arte, nº 8 (2003): 159-226.

${ }^{90}$ Ayala, Sínodo de la Diócesis de Guadix..., título tercero, fol. XXVv.

${ }^{91}$ Además de las obras de arte que María de Hurrutia dejó a los jesuitas, estipuló en su testamento que fueran también para ellos numerosos censos que la señora tenía.

${ }^{92}$ Mariana de la Cueva Benavides fue una pintora nacida en Guadix y fallecida en 1688 en Granada, donde vivía en la colación de San Gil, según recoge Gallego y Burín en su Guía de Granada. Fue elogiada por Antonio Palomino como «excelente pintora de Granada», mujer de D. Francisco de Zayas, caballero de Calatrava, y hermana de otros tres caballeros del mismo hábito. Resultaría de gran interés poder conocer más datos sobre esta pintora nacida en Guadix y sobre su obra. Confiamos en que futuras investigaciones otorguen a esta mujer su lugar en la Historia. 
oratorio; un cuadro de la Santísima Trinidad; otro de Nuestra Señora que va a Egipto; otro de Nuestra Señora labrando un babador y otro de san Joaquín. Un cuadro en tabla cuadrado de Nuestra Señora y el Niño Jesús y san Juan en cueros y Nuestro Señor tiene la cruz. Además de todo ello, una imagen de la Limpia Concepción de bulto que tenía en su oratorio y dos candeleros grandes de plata. A doña María de Carbajal, monja también en ese convento, dejó un cuadro de un santo Cristo crucificado, otro de la cruz a cuestas, y otro del santo Cristo muerto en manos de la Virgen Santísima y cuatro láminas del oratorio.

Finalmente a Luciana Bazán asignó un cuadro de los Reyes y al convento de San Francisco, para su sacristía, un cristo de plata con la cruz de ébano y dos figuras de plata al pie $^{93}$. En total hemos contabilizado un patrimonio artístico formado por 18 cuadros, 14 láminas, 4 esculturas y varios objetos de plata.

Todo ello convierte a doña María de Hurrutia en la mayor «coleccionista» de arte que hayamos podido documentar en Guadix hasta la fecha, además de una gran gestora y promotora de arquitectura tanto civil como religiosa.

\section{Conclusiones}

Las mujeres que hemos documentado pertenecieron, salvo en el caso de la marquesa de Camarasa, a la élite local accitana. Ellas promovieron arquitectura religiosa, entendiendo este acto no solamente como de piedad y devoción cristiana, sino también como medio con el que ensalzar y perpetuar su memoria y la de su linaje. Así, las hemos documentado fundando y construyendo capillas familiares, reparando templos o fundando colegios vinculados a congregaciones religiosas, como el caso del colegio jesuita.

Estando casadas este trabajo lo llevaron a cabo junto a sus maridos. Es por ello que muchos de sus nombres, como el caso de María de Atouguía, han permanecido ocultos tras la figura masculina. Al enviudar y con una libertad similar en algunos aspectos a la que tuvieron los hombres, muchas de ellas dedicaron a la promoción arquitectónica (religiosa y civil) gran parte de sus esfuerzos y riqueza. Al igual que los hombres, estaban obligadas a mantener y reparar sus posesiones, invirtiendo así directamente en el arreglo y mantenimiento de las mismas. En el caso de la construcción de capillas de nueva planta, como es el caso de la de Isabel de Luján, hemos documentado cómo en el siglo XVI las mujeres no sólo daban las directrices, más o menos detalladas, de cómo querían que fueran sus proyectos, sino que evidenciamos que algunas de ellas tenían conocimientos técnicos de arquitectura. Constatamos, también,

\footnotetext{
${ }^{93}$ AHDGu. C. 4006, D. 34, fols. 23r-28r.
} 
cómo la arquitectura religiosa se filtraba en el ámbito doméstico a través de la construcción y dotación de lujosos oratorios; construcciones estas asociadas a las mujeres.

Como queda evidenciado, tanto mujeres como hombres participaron desde el inicio en la cristianización y castellanización de la ciudad medieval islámica de Guadix y en la transformación de su trama urbana. Es por ello y por méritos propios que se merecen su lugar en la Historia.

\section{Bibliografía de los siglos XVI al XVIII}

Álvarez y Baena, José Antonio. Compendio de las grandezas de la coronada villa de Madrid. Madrid: Imprenta de don Antonio de la Sancha, 1786.

Ayala, Martín de. Synodo de la Diocesi de Guadix y de Baça. Alcalá de Henares: Casa de Iuan de Brocar, 1554. Edición facsímil de la Universidad de Granada de 1996 con estudio preliminar de Carlos Asenjo Sedano.

Hariza, Juan de. Descripción genealógica de los excelentísimos señores marqueses de Peñaflor. Écija: Imprenta de Benito Daza, 1772.

Hebrera, Joseph Antonio de. Vida exemplar de la excelentísima señora y venerable madre sor María de las llagas, marquesa de Camarasa y fundadora del insigne y religiosísimo convento del Ángel de la Guarda de la ciudad de Granada de la primera regla de la seráfica madre santa Clara. Zaragoza: Domingo Gascón, impresor, 1698.

Suárez, Pedro. Historia de el Obispado de Guadix y Baza. Madrid: Imprenta de Antonio Román 1696.

Torres, Alonso de. Chrónica de la Santa Provincia de Granada de la regular observancia de nuestro seráfico padre san Francisco. Madrid: Juan García Infançón, impresor, 1683.

\section{Bibliografía general}

Asenjo Sedano, Carlos. Guadix, siglo XV: Plaza de los Corregidores. Granada: Aula de Cultura del Movimiento, 1975.

- La Catedral de Guadix. Guadix: Fundación Caja Rural, Cabildo de la Catedral de Guadix, 1977.

- Guadix, la ciudad musulmana del siglo XV y su transformación en la ciudad neocristiana del siglo XVI. Granada: Diputación Provincial, 1983.

- Episcopologio de la Iglesia Accitana. Guadix: Instituto de Estudios Pedro Suárez, 1990. 
- Arquitectura religiosa y civil en la ciudad de Guadix en el siglo XVI. Granada: Universidad de Granada, 2000.

Díez Jorge, María Elena. «Casas en la Alhambra después de la conquista cristiana (1492-1516): pervivencias medievales y cambios». En La casa medieval en la península ibérica, editado por María Elena Díez Jorge y Julio Navarro Palazón, 395-463. Madrid: Sílex, 2015.

Espinar Moreno, Manuel. «La vida diaria de los repobladores de Guadix en noviembre de 1496». Revista del Centro de Estudios Históricos de Granada y su Reino, $\mathrm{n}^{\circ} 15$ (2001): 35-39.

- «Los moriscos de Guadix y el Cenete en época de Carlos V». En Carlos V. Los moriscos y el Islam, coordinado por María Jesús Rubiera Mata, 127-149. Madrid: Sociedad Estatal para la Conmemoración de los centenarios de Felipe II y Carlos V, 2001.

Espinar Moreno, Manuel, María Angustias Álvarez del Castillo, María Dolores Guerrero Lafuente. La ciudad de Guadix en los siglos XV y XVI (1490-1515). Granada: Ayuntamiento de Guadix, Universidad de Granada, 1992.

Fajardo Ruiz, Antonio, coord. La Catedral de Guadix. Magna Splendore. Granada: Mouliaá, 2007.

Gallego y Burín, Antonio y Alfonso Gamir Sandoval. Los moriscos del Reino de Granada según el Sínodo de Guadix de 1554. Granada: Universidad de Granada, 1996.

García Carraffa, Alberto y Arturo García Carraffa. Enciclopedia heráldica y genealógica hispano-americana. Diccionario heráldico y genealógico de apellidos españoles y americanos. Madrid: Imprenta de Antonio Marzo, 1920-1963.

Gil Calvo, Joaquín. «La iglesia de San Ildefonso y la casa profesa de la Compañía de Jesús en Toledo». En Anales Toledanos, tomo VI, 199-239. Toledo: Diputación Provincial, Instituto Provincial de Investigaciones y Estudios Toledanos, 1973.

Gómez Amezcua, Leovigildo. «La pastoral del bautismo en el Sínodo de 1554». Boletín del Centro de Estudios Pedro Suárez, n 24 (2011): 61-65.

Gómez-Moreno Calera, José Manuel. «La Catedral de Guadix en los siglos XVI y XVII». Cuadernos de Arte de la Universidad de Granada, $\mathrm{n}^{\circ} 18$ (1987): 107-118.

- Arquitectura Mudéjar en la Comarca de Guadix. Guadix: Centro de Iniciativas Turísticas de la Comarca de Guadix, 2009.

- «Diversas precisiones sobre la catedral de Guadix y su ampliación barroca». Cuadernos de Arte de la Universidad de Granada, $\mathrm{n}^{\circ} 40$ (2009): 209-225. 
González Ruiz, Manuel. «Las capellanías españolas en su perspectiva histórica», Revista Española de Derecho Canónico (1950): 475-501.

Jara Torres Navarrete, Ginés de la. Historia de Úbeda en sus documentos. Tomo II: Linajes y hombres ilustres. Úbeda: Asociación Cultural Ubetense «Alfredo Cazabán Laguna», 2005.

Leonardi, Salvatore. «De Portugal a Guadix pasando por Murcia. Datos para la historia de los primeros Barradas». Murgetana, $\mathrm{n}^{\circ} 114$ (2006): 53-106. López Gómez, Óscar. «Tradición y supervivencia política en tiempos de los Reyes Católicos: Juan de Luján, regidor de Madrid, alcaide de Escalona, Gobernador de Elche». En Madrid: su pasado documental, dirigido por Juan Carlos Galende Díaz y Susana Cabezas Fontanilla, 203-227. Madrid: Universidad Complutense, 2015.

López Pérez de Bejarano, María del Pilar. «El oratorio: espacio doméstico en la casa urbana de Santa Fe durante los siglos XVII y XVIII». Ensayos. Historia y Teoría del Arte, no 8 (2003): 159-226.

Marín López, Rafael. «Notas histórico-diplomáticas sobre Capellanías y Cofradías en la Catedral de Granada». Cuadernos de Estudios Medievales y Ciencias y Técnicas Historiográficas, $\mathrm{n}^{\circ} 20$ (1995): 65-92.

Münzer, Jerónimo. Viaje por España y Portugal. Reino de Granada. Introducción de Manuel Espinar Moreno. Granada: Método, 2008.

Passini, Jean. Casas y casas principales urbanas. El espacio doméstico de Toledo a fines de la Edad Media. Toledo: Universidad de Castilla-La Mancha, 2004.

Quesada Martínez, Manuel. «Los Jesuitas en Guadix y su comarca: de las primeras misiones a la fundación del Colegio». En Actas del I Coloquio de Historia "V Centenario de la entrada en Guadix de los Reyes Católicos (1489-1989)”, 157-162. Guadix: Seminario de Historia del I. B. Padre Poveda, 1989.

Robles Vizcaíno, María Socorro. «Las mujeres en la castellanización de Guadix y el Marquesado del Zenete». En Las mujeres en la Historia: Itinerarios por la Provincia de Granada, editado por María Socorro Robles Vizcaíno y Margarita Birriel Salcedo, 221-271. Granada: Universidad de Granada, 2012.

Rodríguez Domingo, José Manuel y Ana María Gómez Román. «El patrimonio artístico del Colegio de San Torcuato de Guadix, de la Compañía de Jesús». Boletín del Centro de Estudios Pedro Suárez, no 12 (1999), 137-160.

Soria Mesa, Enrique. Linajes granadinos. Granada: Diputación Provincial, 2008. 